\title{
J usticia restaurativa y mediación penal intrajudicial en Aragón: condiciones, resistencias e incertidumbres (Restorative J ustice and Mediation Within the Criminal Legal System in Aragon: Conditions, Resistances and Uncertainties)
}

\author{
María J osé Bernuz Beneitez* \\ ANDRÉS GARCÍA INDA*
}

\begin{abstract}
Bernuz Beneitez, M.J., y García Inda, A., 2019. Justicia restaurativa y mediación penal intrajudicial en Aragón: condiciones, resistencias e incertidumbres. Received 10 September 2019, Accepted 24 October 2019. Oñati Socio-Legal Series [online], 9(6), 951-982. Available from: https://doi.org/10.35295/osls.iisl/0000-0000-0000-1088
\end{abstract}

\section{Resumen}

La justicia restaurativa se ha convertido en una filosofía de resolución de conflictos con vocación global, que implica a las partes y procura la responsabilización del agresor y la reparación para las víctimas. Y entre las herramientas para hacerla efectiva en el ámbito judicial penal la más generalizada es la mediación, sobre todo en el contexto europeo. Sin embargo, a la hora de su implantación, no son pocas las resistencias tanto profesionales como institucionales, e incluso por parte de la ciudadanía. Para tratar de profundizar en ellas, y clarificar los retos de las políticas públicas en esta materia, el presente trabajo recoge los resultados de una investigación sociojurídica llevada a cabo en 2019 sobre justicia restaurativa y mediación penal intrajudicial en la Comunidad Autónoma de Aragón.

Este trabajo es el resultado de una investigación socio jurídica llevada cabo en 2019 sobre justicia restaurativa y mediación penal intrajudicial en la Comunidad Autónoma de Aragón (España). La investigación se desarrolló en colaboración con la Asociación ¿Hablamos? y para la misma se solicitó una ayuda del Gobierno de Aragón, en el marco de la Orden PRE/1509/2018, de 17 de septiembre, por la que se hace pública la convocatoria de subvenciones a Colegios Profesionales, Asociaciones sin ánimo de lucro y Fundaciones para la financiación de proyectos en materia de mediación intrajudicial y extrajudicial para el año 2019 (BOA 26/09/2018). Nuestro agradecimiento más sincero a aquellas personas que contribuyeron a mejorar el texto con su lectura pausada y sus comentarios constructivos. Entre ellos, muy especialmente a Carlos Piñeyroa, Sara De Diego, J ordi Bernad, Pilar Bejarano y Pilar Monzón. I gualmente, a la Asociación ¿Hablamos? por su generoso empeño en difundir la filosofía de la justicia restaurativa y de la pacificación social y por hacerla realidad en el ámbito judicial penal y penitenciario (sobre la Asociación, cfr. http://www.asociacionhablamos.es/). La investigación responde además a los objetivos del Proyecto de investigación DER 2017-82173-R GLOBALFUENJ UR (2018-2020) del Programa Estatal de Investigación, Desarrollo e Innovación orientado a los Retos de la sociedad, del Ministerio de Economía, Industria y Competitividad.

* María J osé Bernuz Beneitez es profesora Titular de Filosofía del Derecho de la Universidad de Zaragoza donde imparte clases en el Grado en Derecho y en el Máster en Sociología de las Políticas Públicas y Sociales. Su investigación se ha centrado principalmente en el ámbito de la justicia juvenil, los derechos de la infancia y la adolescencia, las políticas de seguridad o la justicia restaurativa. Datos de contacto: Facultad de Derecho, Universidad de Zaragoza. Calle Pedro Cerbuna s/n. E-50009. Zaragoza (España). Dirección de email: mbernuz@unizar.es ORCID: https://orcid.org/0000-0001-7723-5172

* Andrés García Inda es profesor Titular de Filosofía del Derecho en la Universidad de Zaragoza y miembro del Laboratorio de Sociología Jurídica (grupo consolidado de investigación reconocido por el Gobierno de Aragón). Ha publicado estudios sobre el Derecho y la teoría social, las políticas sociales y el derecho, el voluntariado y los derechos humanos. Datos de contacto: Facultad de Derecho, Universidad de Zaragoza. Calle Pedro Cerbuna s/n. E-50009. Zaragoza (España). Dirección de email: agi@unizar.es ORCID: https://orcid.org/0000-0002-4620-9884 


\title{
Palabras clave
}

Justicia restaurativa; mediación penal; facilitadores; operadores jurídicos; justicia penal

\begin{abstract}
Restorative justice has become a conflict-solving philosophy with a global vocation, involving the parties and aiming for the accountability of the aggressor and reparation for the victims. Among the tools to implement it in the criminal judicial scope, the most extended is mediation, especially in Europe. However, there are many resistances to its implementation, both from the profession and from the institutions, and even from the people. In order to take a deeper look into these resistances, and to clarify the challenges that public policies are facing, this paper presents the findings of a socio-legal research carried out in 2019 about restorative justice and criminal mediation within the judiciary in the Autonomous Community of Aragon (Spain).
\end{abstract}

\section{Key words}

Restorative justice; criminal mediation; facilitators; legal operators; criminal justice 


\section{Índice / Table of contents}

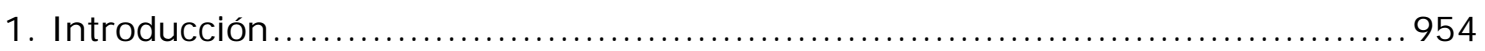

2. ¿De qué hablamos cuando hablamos de mediación? ........................... 957

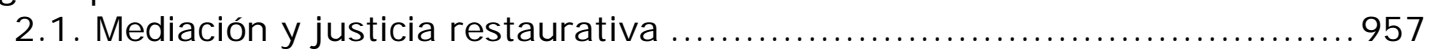

2.2. Mediación restaurativa: proceso y resultado ................................ 959

2.3. Complementariedad o no de la justicia penal ........................... 960

3. La mediación penal como algo problemático: condiciones, resistencias e

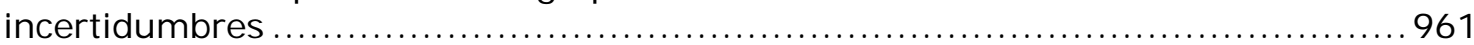

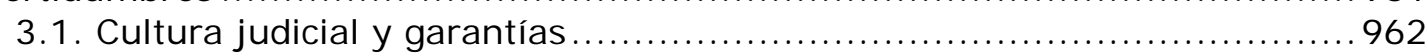

3.2. ¿Autonomía y "privatización" del delito? ¿Qué delitos? ........................963

3.3. Cultura social y mediación................................................. 965

3.4. La mediación penal intrajudicial: ¿una cuestión de "buena voluntad"? ....966

4. Integrar la justicia restaurativa en el proceso penal ............................. 967

4.1. Encajar la mediación en las estructuras del proceso penal .................967

4.2. Protocolizar o no protocolizar: esa es la cuestión............................ 970

5. Propuestas para mejorar la credibilidad de la mediación penal intrajudicial ....972

5.1. Profesionalizar la mediación penal intrajudicial:

¿qué es un buen facilitador?............................................... 972

5.2. ¿A qué aspira la mediación intrajudicial? ¿Cuándo estamos ante una

mediación exitosa? ............................................................. 975

5.3. Las reticencias entre profesionales (abogados y mediadores):

¿de quién es la mediación? ............................................................996 976

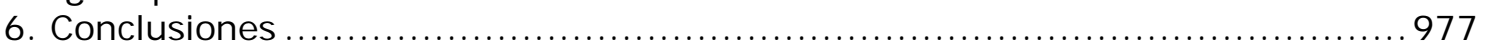

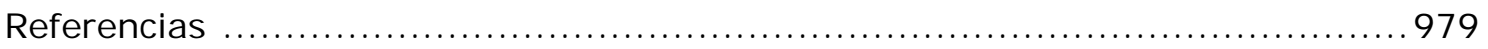

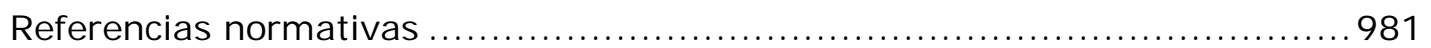




\section{I ntroducción}

La justicia restaurativa se ha convertido en una filosofía de solución de conflictos global que ha llegado a todos los continentes, parece que tiene cabida en diferentes culturas y aspira a integrarse (o no) en distintas familias jurídicas. Aunque la forma comunitaria y participativa de resolver conflictos forma parte de la historia de la humanidad, la consolidación de la justicia restaurativa como tal se produce en los años setenta como un intento de colmar algunas carencias del sistema de justicia penal que tienen que ver, entre otras cuestiones, con la expulsión de las partes y de la comunidad de los procesos de solución de conflictos generados con la comisión de un delito, la escasa responsabilización del agresor a través del proceso y el castigo penales o la nula reparación del daño causado a la víctima. Como contrapartida, la justicia restaurativa apuesta por intentar integrar a las partes afectadas por la comisión de un delito en un diálogo mediado por alguien que lo facilita, en el que la víctima cuente cómo se ha sentido tras el delito y formule las preguntas que han quedado sin respuesta y el agresor dé su versión de los hechos (sin exculparse) y escuche a la víctima, para llegar a una solución acordada por ambas partes. Algo que permitirá tanto reparar el daño causado de forma significativa para todos, como responsabilizar al agresor del mismo. ${ }^{1}$

Las herramientas para hacer efectiva la filosofía de la justicia son múltiples y deben adaptarse a los supuestos a resolver y a las circunstancias de las partes implicadas. $\mathrm{Si}$ dejamos aparte los círculos restaurativos o las conferencias familiares, la mediación es la herramienta más generalizada en el contexto europeo. De hecho, la referencia a la mediación se ha convertido en los últimos años (o décadas) en una especie de talismán, sobre todo en el mundo jurídico, al que se acude como un recurso indispensable para la mejor resolución de los conflictos sociales. Vivimos un auténtico boom de la mediación, en la que se confía como un remedio esencial, tanto de carácter extrajudicial como intrajudicial, para resolver algunos de los problemas estructurales de la justicia. De ahí que a la iniciativa social y el interés académico por la cuestión se haya sumado la intervención de los poderes públicos, para desarrollar políticas tendentes al fomento de la mediación como un recurso útil y necesario en el ámbito de la Administración de Justicia.

Es evidente que a ese incremento en el interés social y político por la mediación ha contribuido la consolidación de la misma a través de la normativa internacional primero y, en nuestro caso, nacional después. Naciones Unidas, al igual que el Consejo de Europa llevan haciendo referencia, a través de sus distintas instancias, a la mediación y la justicia restaurativa desde la década de los 80 en aquellas cuestiones relacionadas con la justicia penal. En el ámbito europeo, la declaración más definitiva en el apoyo a la justicia restaurativa ha sido la Directiva 2012/29/UE, del Parlamento Europeo y del Consejo de 25 de octubre de 2012, que establece algunas pautas para la implementación de la justicia restaurativa en los estados miembros, o la Recomendación CM Rec 2018(8) del Comité de Ministros a los Estados miembros en materia de mediación penal en la que se hacen unas indicaciones a la hora de legislar en justicia restaurativa. En España, la consecuencia directa de esa Directiva ha sido la promulgación del Estatuto de la Víctima (aprobado por Ley 4/2015, de 27 de abril) que reconoce el derecho a la víctima a acceder a Servicios de Justicia restaurativa.

Sin embargo, no son pocas las dudas y los interrogantes que suscita ese aparente auge del fenómeno de la mediación y las políticas públicas dirigidas al fomento de la misma. Al tiempo que siguen existiendo resistencias profesionales, institucionales y también ciudadanas a la implantación de la mediación penal intrajudicial como una forma de resolver conflictos que llegan ante los juzgados de lo penal. Algo que ha fomentado una implementación muy desigual de la justicia restaurativa y la

\footnotetext{
${ }^{1}$ Sobre el concepto de justicia restaurativa, modelos y herramientas se ha producido una extensísima literatura, tanto en revistas especializadas, como en manuales. Se puede consultar, por ejemplo, por su exhaustividad y claridad, el manual de Johnstone y Van Ness (2007).
} 
mediación penal en el territorio español. De ahí la necesidad de analizar y clarificar hacia dónde deberían orientarse tales políticas, tanto cuantitativamente, por así decirlo (esto es, hacia una mayor implantación, en su caso, de la institución de la mediación en la Justicia), como cualitativamente, es decir, hacia una mejor mediación, dadas las resistencias y los conflictos que suscita - sobre todo en el ámbito jurisdiccional penal- la incorporación de la misma en el proceso. Entre otras razones porque buena parte de esas dudas y dificultades tienen que ver con las confusiones existentes en torno a la propia noción de lo que la mediación es o puede ser y aportar, tanto en el marco del proceso judicial como fuera de él. Al tiempo que no se tiene muy clara la filosofía restaurativa subyacente a la mediación o se confunde aquélla con ésta.

Son esas reticencias que no acaban de vencerse las que nos hicieron plantearnos esta investigación exploratoria que nos permita conocer el estado de la mediación penal en Aragón. En la Comunidad Autónoma de Aragón, las primeras experiencias de mediación penal intrajudicial empezaron a desarrollarse en el año 2006 por iniciativa de la Asociación ¿Hablamos?, en el marco de la experiencia piloto que había impulsado el Consejo General del Poder Judicial (CGPJ), siendo la tercera experiencia en el contexto nacional de este tipo, después de Cataluña y Madrid (Piñeyroa et al. 2011). Esa iniciativa se fue extendiendo por diferentes juzgados acompañada de una labor divulgativa que permitiera dar a conocer la filosofía de la justicia restaurativa y los objetivos de la mediación en el marco del proceso penal.

En septiembre de 2011, la Asociación ¿Hablamos? compareció a petición propia ante la Comisión de Peticiones de las Cortes de Aragón solicitando avances institucionales en el campo de la Justicia Restaurativa en Aragón y en concreto en el ámbito de la mediación penal. Petición que fue recogida por la Comisión Institucional de las Cortes de Aragón, que aprobó en noviembre por unanimidad la Proposición no de Ley no 75/11-VIII por la que se instaba al Gobierno de Aragón a continuar con la aplicación de la Justicia Restaurativa en la Comunidad, de manera que se extendieran las buenas prácticas de la mediación penal desarrollada a todos los juzgados del territorio aragonés. Fruto de esa encomienda surgió el Convenio de Justicia Restaurativa y de expansión gradual de la Mediación Penal al conjunto de juzgados de instrucción y primera instancia de la Comunidad Autónoma de Aragón, liderado por la Dirección General de Administración de Justicia del Departamento de Presidencia y Justicia del Gobierno de Aragón, que, de nuevo con la participación del CGPJ y la Fiscalía del Tribunal Superior Justicia de Aragón, se firma a cuatro bandas en el año 2012 y en el que se recoge todo el acervo de conocimiento y experiencia que el modelo aragonés, pionero en el ámbito español, y reconocido nacional e internacionalmente, había venido desplegando de manera altruista hasta el momento en la Comunidad Autónoma. Ese mismo año el Colegio de Abogados de Huesca firmó con el CGPJ un Convenio para la implantación de un Servicio de Mediación Intrajudicial Familiar y Penal en los Juzgados de Barbastro y Monzón, con el que se inicia la actividad de mediación penal intrajudicial en ambos partidos judiciales por parte de dicho Colegio Profesional. En abril de 2015 se firma el Convenio marco de Colaboración para la promoción de la mediación intrajudicial entre el CGPJ y la Comunidad Autónoma de Aragón y en 2018 la Asociación ¿Hablamos? obtiene en concurrencia competitiva el desarrollo de una "experiencia piloto" de mediación penal intrajudicial en la totalidad del territorio aragonés; que se repite en 2019.

A lo largo de todos estos años (entre 2007 y 2019) se han llevado a cabo 277 expedientes de mediación penal intrajudicial, de los que se llegó a mediar efectivamente en un $69 \%$ de los casos y se consiguió un acuerdo en casi un $42 \%$ (116 casos). En el resto, como luego tendremos ocasión de comentar, o bien no se llegó a un acuerdo entre las partes o bien estas desistieron en algún momento de seguir adelante con el diálogo. Evidentemente, las cifras siguen siendo muy pequeñas en comparación con el volumen de casos que llegan a los juzgados de la Comunidad Autónoma, pero es indicativa de las posibilidades reales de la mediación restaurativa. Además, el hecho de que se persista en esas cifras, o de que estas no hayan 
aumentado significativamente en los últimos años, ${ }^{2}$ también invita a reflexionar sobre el alcance real de las políticas públicas en este tema.

¿Qué elementos debemos considerar para llevar a cabo esa reflexión?, ¿Cómo evaluar la experiencia de esos años?, ¿Cuál es el alcance y el resultado de ese trabajo?, ¿En qué medida las políticas públicas en materia de justicia han contribuido al desarrollo de la mediación como una herramienta de justicia restaurativa?, o ¿Hasta qué punto tales políticas pueden convertirse en un obstáculo para ello? Para responder a esas y otras cuestiones se diseñó el proyecto de investigación sobre La mediación penal intrajudicial en Aragón (2008-2018): experiencia y perspectivas de futuro, cuyo objetivo principal era "investigar el alcance y resultados de las experiencias desarrolladas en materia de mediación penal intrajudicial en el ámbito de toda la Comunidad Autónoma de Aragón en la última década", y para ello se solicitó la ayuda al Gobierno de Aragón. Entre los objetivos más específicos de la investigación estaba fundamentalmente conocer cuál es la idea o el concepto de mediación con el que trabajan los operadores jurídicos y los mediadores en la comunidad autónoma aragonesa para comprender su identidad o no con la filosofía restaurativa. Además, nos parecía importante averiguar los motivos que están en la base de las resistencias de los operadores jurídicos a integrar la mediación en el sistema penal. Por último, con una pretensión constructiva, se aspiraba a conocer los elementos que, a juicio de los prácticos de la mediación, permiten considerarla como exitosa.

Para el logro de esos objetivos generales se ha apostado por una metodología cualitativa, desarrollada mediante dos grupos de discusión que nos permitan conocer la opinión individual, pero construida colectiva, y espontáneamente (no dirigida), de los participantes en cada uno de los grupos. En concreto, se organizaron dos grupos de discusión en los que abordaron tres bloques temáticos bastante amplios que nos permitieran responder a nuestros objetivos: a) ¿qué es la mediación? ¿qué aporta? ¿qué limitaciones tiene? ¿qué hay detrás de la mediación?; b) ¿qué necesita una mediación para que la demos por buena o correcta? ¿qué necesita un mediador para desarrollar adecuadamente su función? y c) ¿qué futuro tiene la mediación? El primer grupo (GD1) se reunió el día 20 de marzo de 2019 en la Facultad de Derecho de la Universidad de Zaragoza y reunió a operadores jurídicos con alguna experiencia en el ámbito de la mediación penal intrajudicial, principalmente jueces, fiscales y letrados de la Administración de Justicia. El segundo grupo (GD2) se reunió el día 22 de marzo de ese mismo año, también en la Facultad de Derecho y en él participaron mediadores con experiencia en la mediación penal principalmente (aunque también civil), y con diversidad de formaciones (juristas, psicólogos...). ${ }^{3}$

Es evidente que los temas que emergen en un grupo de discusión no son todos los temas que preocupan a sus integrantes y que otros grupos quizás hubieran hecho emerger otro tipo de cuestiones. Sin embargo, los resultados nos parecen significativos y nos permiten avanzar algunas conclusiones que apuntan a las razones que bloquean un desarrollo más pleno de la mediación en esta Comunidad Autónoma y que, seguramente, las preocupaciones y el análisis resultarán comparables con las de otros contextos similares. Este trabajo ha intentado sistematizar los resultados de estos grupos, siendo conscientes de que han quedado fuera una gran cantidad de debates abiertos en torno a la justicia restaurativa y la mediación como uno de sus métodos más habituales.

\footnotetext{
${ }^{2}$ Coincidentes con el plan institucional para impulsar la mediación intrajudicial: https://www.aragon.es//administracion-de-justicia- 1

${ }^{3}$ Es obvio que sin la colaboración desinteresada de los participantes en los grupos de discusión este trabajo no sería posible. Gracias por dedicarnos su tiempo para abrir un tiempo de diálogo en torno al presente y el futuro de la mediación penal intrajudicial. También nuestro agradecimiento más sincero para Cruz Félez García por haber transcrito íntegramente los grupos de discusión.
} 


\section{2. ¿De qué hablamos cuando hablamos de mediación?}

Quizás la cuestión primigenia por la que es preciso comenzar si queremos comprender qué ocurre con la mediación es por aclarar qué entienden por mediación los operadores jurídicos y mediadores. Por ejemplo, al igual que ocurre en otros ámbitos, también en el caso de la justicia penal se tiende a confundir habitualmente la mediación con la negociación. Y sin embargo es claro que mediación no es lo mismo que negociación; o no es lo que habitualmente se entiende por negociación (y con lo que tiende a confundirse). O por ser más precisos: no es cualquier tipo de negociación. Con carácter general se ha dicho que la mediación es una "institución orientada a garantizar que las partes protagonicen un buen debate negocial; o, dicho en otras palabras, es una institución orientada a suplir los déficits de racionalidad de las partes que les impiden debatir correctamente las posibilidades de alcanzar un acuerdo" (Aguiló 2015, 105). En ese sentido, la mediación es un sistema o método autocompositivo y no adversativo de resolución de conflictos, que no está basado en la confrontación sino, sobre todo, en el acuerdo, por lo que el punto de partida es la igualdad de las partes (Martín Diz 2010, 60-61 y 69). Pero algunas de esas características parecen chocar tanto con la cultura profesional de los juristas como con la lógica procesal y los principios de la jurisdicción penal. Y de ahí la necesidad de clarificar de entrada cuál es el sentido de dicha institución en el ámbito penal: ¿de qué hablamos cuando hablamos de mediación?

\subsection{Mediación y justicia restaurativa}

Los operadores jurídicos siguen considerando la mediación penal intrajudicial como algo "novedoso" y "problemático", a pesar de la amplia experiencia existente tanto en España como en Aragón (Ríos y Olavarría 2008, Piñeyroa et al. 2011). Ambos adjetivos parecen ir estrechamente unidos. Es esa novedad o diferencia que la mediación introduce - vinculada a la noción de justicia restaurativa- la que choca o entra en conflicto con la cultura jurídica, tanto de los profesionales del derecho como de la ciudadanía en general, que tienden a verlo como algo incierto.

Sin embargo, sí que existe un amplio consenso entre los profesionales directamente implicados en la implantación de la mediación penal intrajudicial en vincular la institución de la mediación a la idea de justicia restaurativa. La mediación tiene sentido como herramienta al servicio de ese objetivo, y no de otros. Aunque también parecen denotar que la mediación es algo más sencillo que el logro de la justicia restaurativa que está en otro escalón por encima, que aspira a objetivos más ambiciosos.

De alguna manera se da a entender que la mediación en el proceso penal tiene sentido como una herramienta para favorecer las dimensiones restaurativas de la justicia a las que el procedimiento judicial en ocasiones no llega, como son las necesidades de participación y resarcimiento emocional y moral de la víctima:

... el planteamiento de cómo afrontas las necesidades de las personas que están en esas situaciones es tan distinto, porque el planteamiento habitual de la justicia tradicional es qué precepto han infringido, lo clásico, quién lo ha infringido y qué castigo merece. Claro, entonces la mediación es que es otro mundo, entonces ahí yo creo que abre unas posibilidades enormes, sobre todo para atender las necesidades de la víctima, por supuesto, que en el sistema tradicional está maltratada, y también del agresor, lógicamente, y luego, dentro de la justicia restaurativa me parece apasionante el camino, qué camino abre a la comunidad, es decir, a todas las demás personas, o que pueden participar en lo que ha ocurrido o que tienen algún tipo de intervención (...). (GD2)

Así, como los propios intervinientes reconocen, la introducción de la mediación en el proceso tiene otros efectos positivos pero que podríamos llamar "indirectos", relativos a cómo se gestiona el conflicto en el marco del procedimiento. Así, se subrayan los efectos pacificadores entre las partes que la experiencia mediadora suele conllevar. Incluso sin conseguir un acuerdo entre ellas, los operadores jurídicos 
insisten en que cuando la mediación se introduce en el proceso, el procedimiento judicial continúa de otro modo, con otro ambiente, menos enconado o violento. De alguna manera, la mera intención o existencia del diálogo es ya un éxito. Eso también se traduce en un ahorro económico o de tiempo para las partes.

Pero en cualquier caso el objetivo de la mediación penal, si aspira a ser restaurativa, no es (no debe ser) fundamentalmente económico, ni para las partes ni para el proceso. Como tampoco lo es "descargar" o aliviar la congestión formal o estructural del sistema penal (aunque también pueda tener esos efectos). Como asegura Varona $(2019,32)$, "es una justicia que no es rápida ni productivista, sino más bien sosegada y procedimental. Implica pararse: pararse a escuchar y entender a las víctimas, respetando sus tiempos y sin instrumentalizarlas". El efecto directo de la mediación es fomentar, mediante el diálogo entre las partes, una restauración o reparación del daño que produce el delito, que sea significativa para ambas. Como bien dice J osep Aguiló $(2015,97)$, la mediación penal intrajudicial "se considera como un mecanismo adecuado, eficaz, para resolver los conflictos emocionales y de todo tipo que el proceso judicial no es capaz de gestionar de manera satisfactoria debido a su excesiva burocratización. (...) es vista como un remedio no tanto para la desmesurada cantidad de asuntos que llegan a la jurisdicción cuanto al problema de la excesiva rigidez del proceso judicial".

Esa dimensión emocional de la mediación es expresa y repetidamente mencionada por los intervinientes en los grupos de discusión. La posibilidad de una intervención mediadora abre una puerta a la expresión y la gestión de emociones que el procedimiento judicial oculta o ahoga, de manera que pueda hacerse real la reparación, al menos moral, del daño causado y abrirse una puerta, aunque sea pequeña, para que el agresor asuma responsablemente su conducta. ${ }^{4}$ Se mencionan sobre todo dos emociones básicas que la mediación ayuda a gestionar y "curar" del algún modo: la vergüenza (del lado del agresor o victimario) y el miedo (de parte de la víctima): ${ }^{5}$

... esas dos emociones en la mediación se pueden trabajar de alguna forma que desde luego el procedimiento clásico no te va a facilitar de ninguna, al revés. (GD2)

Hay autores que critican la atención cuasi-exclusiva a ese aspecto terapéutico de la mediación (así lo hace por ejemplo Martín Diz 2010, 324-327). En parte, por una visión excesivamente reduccionista de la noción de justicia restaurativa y de la mediación como sistema complementario dirigido fundamentalmente a la solución del conflicto. Porque realmente el objetivo de la mediación restaurativa es contribuir a esa solución, pero atendiendo a aquellas dimensiones que actualmente el proceso judicial, en ocasiones, no atiende de un modo adecuado. Pero tampoco cabe confundir la mediación con lo que sería una intervención estricta y técnicamente terapéutica (de carácter psicológico, por ejemplo) con las partes. De hecho la mediación tampoco es la única herramienta posible de justicia restaurativa; existen otras herramientas posibles (círculos restaurativos, conferencias, encuentros...) que también tienen como objetivo el reconocimiento y la reparación del daño causado y que integran a otras partes (familiares, amistades, comunidad...) que puedan haber sido afectadas por el delito o que puedan estar interesadas en su solución.

La mediación penal es un instrumento de pacificación entre las partes (e incluso de pacificación social) a través del diálogo, que no se centra únicamente en la solución del conflicto desde la perspectiva del ius puniendi del Estado, sino que atiende fundamentalmente a las necesidades e intereses de la víctima y busca que el agresor pueda comprender y asumir su responsabilidad por el daño causado. Por eso, la mediación tiene en ese sentido una doble composición de solución y restauración,

\footnotetext{
${ }^{4}$ De hecho, el contenido de la mayoría de los acuerdos alcanzados en las experiencias de mediación es de tipo ético o moral $(50 \%)$, relacionados con el reconocimiento de la responsabilidad, la información, la petición de disculpas, etc.; en un 33\% de los casos también se incluyen medidas relacionales y en un $12 \%$ reparaciones de contenido económico (Asociación ¿Hablamos? 2018).

5 Sobre las necesidades de las víctimas puede verse Bennett 2007.
} 
con especial énfasis en esta segunda dimensión. Con otras palabras, se trata de alcanzar una solución del conflicto que sea restaurativa, lo que no siempre se consigue. Porque si bien el acuerdo entre las partes es un objetivo fundamental de la mediación, tampoco deben confundirse las dos cosas.

\subsection{Mediación restaurativa: proceso y resultado}

Dicho en otros términos, en el caso de la mediación penal intrajudicial que aspira a ser restaurativa tan importante es el resultado a alcanzar como el proceso a seguir. Con carácter general, aproximadamente la mitad de las mediaciones efectivamente realizadas llegan a plasmarse en un acuerdo entre las partes. Sin embargo, los participantes en los grupos de discusión previenen de lo que podríamos llamar la "obsesión por el acuerdo", a la hora de trabajar con las partes, pero sobre todo a la hora de convencer a las instituciones o a los compañeros no convencidos de las ventajas que ofrece la mediación. Esa obsesión por el resultado inmediato del pacto entre las partes que se sella con un acuerdo de mediación puede perjudicar el buen desarrollo de la misma y podría pervertir la esencia restaurativa de la mediación que se proyecta a más largo plazo. Recuerda por ejemplo una mediadora:

... el objetivo no es el acuerdo, el objetivo es esa pacificación en el conflicto y finalmente si se llega eso a plasmar y a recoger en un acuerdo, perfecto; pero si no, ya es mucho. $Y$ de hecho, un poco lo que nos transmiten los jueces y juezas con los que colaboramos es que en los casos en los que ha habido encuentro, aunque no se haya llegado finalmente a un acuerdo, se nota, y en Sala se nota. Es un poco lo que decía de volverse a humanizar, estas personas se vuelven a llamar por su nombre, o se vuelven a mirar, cosa que en un origen no se había producido, o cuando llegaron al juzgado no era así. (GD2)

Desde la perspectiva de la gestión y promoción pública de los procesos de mediación, esa "obsesión por el acuerdo" puede traducirse en una evaluación de la mediación excesivamente simplista, dirigida únicamente a contabilizar el número de acuerdos que se producen, sin tener en cuenta los efectos que los procesos restaurativos tienen incluso cuando no se produce acuerdo. Si solo nos centramos en los acuerdos logrados, quedarían sin evaluar aspectos como la satisfacción de las partes con el proceso mediador, la capacidad del proceso para restaurar relaciones o la capacidad de los mediadores para dirigir la mediación de acuerdo con valores restaurativos (Gavrielides 2007, 257-258). Además, el llegar "al acuerdo por el acuerdo" corre el riesgo de olvidar que el conflicto también es el resultado de un proceso y un contexto al que hay que atender. Como reconocen los propios operadores jurídicos, el caso que llega al juzgado es la punta del iceberg de una situación conflictiva que lleva un tiempo enquistada: "hay ya una situación, una relación deteriorada, de unos meses o unos años ya (...) a lo mejor salta la chispa por algo (...) una tontería" (GD1). No se trata únicamente de "resolver" el caso planteado, sino de cuidar con una perspectiva más sistémica la relación en la que se ha dado el caso, sobre todo cuando se trata de relaciones que se van a mantener en el tiempo (familiares, laborales, vecinales...). De hecho, reconocen que, a veces, aunque no se resuelva el tema por el que se llega al juzgado la mediación "sirve para solucionar este concreto conflicto familiar" (GD2).

Porque bueno, igual en otros casos, pues el modelo quizá que se escoja de mediación pues puede ser más, menos importante, porque al final, pues bueno, se consigue o no llegar a acuerdos, pero ya está, luego cada uno se marcha por esa puerta y ya está. Pero yo creo que cuando hay relaciones que se van a mantener en el tiempo debería ser más importante que se primara el modelo que se utiliza de mediación. (G2)

Detrás de esas palabras late un modelo de mediación que da protagonismo al eventual proceso de diálogo y que aspira a ser "transformativa". Se entiende que no debe confundirse, por lo tanto, la mediación penal intrajudicial (con esa orientación transformadora) con otras fórmulas de conciliación y negociación de intereses. Hay incluso quienes manifiestan algunas reticencias a hablar de mediación, a utilizar ese 
término en el ámbito penal por las connotaciones que tiene en el ámbito civil y mercantil:

...cuando hay una mediación civil uno está admitiendo que va a perder algo a cambio de ganar algo (...). Cuando hablamos de mediación penal no estamos pensando en que la víctima ceda algo para que, en todo caso podemos pensar que gana algo el sistema porque consigue una condena más rápida y por eso estamos dispuestos a renunciar o ceder en parte del castigo (...). Por eso a mí el término mediación en este ámbito no me gusta, porque no es un pacto de cesiones mutuas, es más desde el punto de vista de cómo reparamos a la víctima. (GD1)

\subsection{Complementariedad o no de la justicia penal}

La mediación penal es, por sus cualidades, percibida como una herramienta o institución útil para complementar el ius puniendi de la Administración de Justicia. Sobre todo porque, como veremos, así lo entiende la legislación penal y procesal. Su introducción en el marco procesal penal tiene sentido porque no suple la función punitiva del Estado, sino que trata de complementarla en sus aspectos restaurativos o reparadores. Entre otras razones porque la potestad punitiva y el proceso penal también tienen entre sus fines la reparación del daño (Gil Gil 2016) y la responsabilidad y rehabilitación del infractor, así como, en última instancia, la prevención de la delincuencia y la reincidencia. La mediación penal pretende ser una herramienta que favorezca la consecución de esos fines. Cuál debe ser el alcance o el engarce de ese complemento en el marco del proceso es lo que resulta complicado:

\footnotetext{
- ... hay una dimensión que es el ius puniendi, la prevención general y especial, pero hay otra que es la víctima, y que es la reparación, y ahí sí está en conflicto abierto, y eso es lo que sí es susceptible de mediación y eso es lo que habría que ver. Ahora bien, ¿esa reparación tiene que tener necesariamente repercusión en el castigo?

- Pues no tiene por qué tenerla siempre.

- Yo creo que sí, que debería tenerla. (GD1)
}

Así pues, la mediación restaurativa no es la respuesta al conflicto, sino una parte de la misma. Como tal, además, no es una herramienta que pueda utilizarse en cualquier momento procesal, ni en todos los casos. Tanto jueces y fiscales como abogados y mediadores coinciden en que "no sirve para todo" (GD2), que "no todo es mediable" (GD1). Lo que no quiere decir que muchas cosas que no se consideran objeto de la mediación, o que han sido prohibidas por ley (como es el caso de la violencia de género), no puedan serlo.

Si la mediación tiene sentido dentro del proceso es porque puede facilitar la gestión de aquellos aspectos (fundamentalmente emocionales) que la rigidez formal del procedimiento no atiende adecuadamente. Y ahí radica, de hecho, una de las paradojas o tensiones de la mediación intrajudicial. Por un lado, porque esa burocratización formal -que va dirigida al reconocimiento de garantías fundamentales en el proceso que permiten calificar al juicio como justo- puede constituir un obstáculo a la misma implantación de una herramienta que se caracteriza (debe caracterizarse) por la adaptación a las circunstancias del caso y las necesidades y demandas de las partes. Por otro, por el riesgo de que la incorporación al proceso con las exigencias derivadas de esa incorporación (protocolización) deriven en una cierta burocratización formal de la propia mediación, que difumine sus efectos restaurativos y la convierta en un mero mecanismo de simplificación o legitimación procesal (economía y pacificación procesal, "compra de atenuantes", etc.) que no cumplirá con los fines restaurativos a los que aspira.

Puede resultar llamativo que en el debate de los operadores jurídicos no se plantee la cuestión del impacto (positivo) que la mediación penal puede tener en la sociedad, y que suele destacarse en la literatura especializada. Aunque no hay demasiados datos al respecto, desde el punto de vista político todo parece apuntar a ciertos efectos benéficos generales de la mediación restaurativa como elemento de 
pacificación social. ${ }^{6}$ El enfoque más estrictamente técnico de los operadores jurídicos, dirigido a ver cómo encajar la mediación en las condiciones procesales, podría hacer olvidar ese impacto. Pero también podría verse limitada en ocasiones la intervención pública, más preocupada por aliviar la congestión del sistema judicial a través de estrategias o herramientas informales de resolución de conflictos, que por fomentar los efectos restaurativos de tales herramientas.

\section{La mediación penal como algo problemático: condiciones, resistencias e incertidumbres}

Vistos los efectos positivos que tiene la mediación penal intrajudicial y la buena valoración que hacen de la misma los operadores jurídicos (como herramienta para complementar la dimensión restaurativa del proceso), ¿por qué esta resulta también, como ellos mismos dicen, "problemática"?, ¿de dónde nacen esos problemas?, ¿cuáles son las dificultades o limitaciones que condicionan su desarrollo e implantación?

La incertidumbre en la que se mueve actualmente, al menos en Aragón, la mediación penal intrajudicial tiene que ver con tres grandes tipos de dificultades 0 condicionantes que podemos identificar al analizar los discursos de los diferentes operadores jurídicos implicados (jueces y fiscales, letrados de la administración de justicia, abogados y mediadores):

- En primer lugar hacen referencia a lo que podríamos llamar condiciones "técnico-jurídicas", relativas fundamentalmente al engarce de la mediación dentro del procedimiento judicial (competencia e iniciativa, alcance material, tiempos, efectos procesales, etc.). Jueces y fiscales insisten en señalar que "tenemos un procedimiento encorsetado" (GD1) que dificulta enormemente el desarrollo de la mediación penal.

- En segundo lugar, las dificultades de tipo cultural, tanto relativas a la cultura profesional de los operadores jurídicos como, en un sentido más amplio, a la percepción y las expectativas sociales sobre el proceso judicial. Todos los intervinientes en los grupos de discusión se muestran de acuerdo al insistir, en diferentes momentos, en que "nos falta cultura y pedagogía" relacionada con la mediación y la justicia restaurativa, el derecho colaborativo, la resolución pacífica de conflictos, etc. En esa línea, Varona $(2019,34)$ apunta que "el techo de cristal de la justicia restaurativa es, sin duda, la cultura jurídica de profesionales y de sociedad, en relación con el entendimiento de su significado".

- Por último, podríamos señalar otros condicionantes de carácter político que tendrían que ver con la orientación y las limitaciones de las políticas públicas en materia de justicia y, más concretamente, relacionadas con la ordenación y la implantación de los programas de mediación penal intrajudicial (objetivos, diseño, recursos, criterios de evaluación, etc.). Estas limitaciones de las políticas públicas relacionadas con la mediación abocan al voluntarismo y el buenismo en la implementación de la mediación penal. Esos dos son los rasgos que, según jueces, fiscales, abogados y mediadores, caracterizan actualmente, desde su experiencia, los programas de mediación penal intrajudicial, sostenidos más por la "buena voluntad" de algunos profesionales (jueces, fiscales y mediadores) que por la existencia de una política pública definida claramente, coherente y sostenida en el tiempo.

Evidentemente los tres tipos de condicionantes están estrechamente relacionados. Por ejemplo, si existen determinadas resistencias de tipo cultural (por ejemplo, entre los profesionales del derecho) es también porque trabajamos acostumbrados a un determinado entorno técnico. Y además estos tres tipos de condicionantes definen

${ }^{6}$ Véase el estudio de Igartua y coautores/as $(2015,53-61)$ en el que se indican los aspectos que las personas encuestadas consideraron como positivos en su contacto con la justicia restaurativa. 
tanto las resistencias que hoy día nos encontramos al desarrollo de la mediación penal intrajudicial, como las condiciones de oportunidad para la misma. En ese sentido, hay que distinguir los valores y las garantías que entrañan tales condicionantes de los miedos o las limitaciones derivadas de la resistencia al cambio (o de la simple incompetencia). Veamos algo más detenidamente algunas de esas implicaciones.

\subsection{Cultura judicial y garantías}

Hablar de las condiciones técnico-jurídicas de desarrollo de la mediación penal intrajudicial puede llevar al error de pensar que éstas únicamente hacen referencia a cuestiones de carácter procedimental, meramente formal, que obstaculizan el diálogo que la mediación penal trata de introducir entre las partes. Evidentemente algunos de esos condicionantes pueden ser simplemente procedimentales, y buena parte de las observaciones críticas que hacen los jueces y fiscales intervinientes en los grupos de discusión tienen que ver con la necesidad de limar o suavizar y, sobre todo, clarificar las condiciones formales de desarrollo de la mediación penal intrajudicial. Pero en realidad esas preocupaciones aparentemente formales señalan cuestiones materiales relativas a valores jurisdiccionales de carácter fundamental como es el de garantizar la seguridad jurídica.

Esa seguridad jurídica, que es una de las condiciones mínimas de la justicia, se quiebra cuando, a falta de una política pública clara, la posibilidad de la mediación penal queda al albur de la buena voluntad del juez o fiscal de turno:

Siempre estamos a expensas pues de tener un juez más o menos favorable a la mediación, más o menos conocedor. (GD2)

O cuando las condiciones procesales no facilitan el desarrollo de la mediación:

... es bueno que a la víctima se le reconozca un papel preponderante, que se le pida perdón; es bueno que el reo, el delincuente, asuma su responsabilidad; pero cómo podemos hacer para que el proceso penal de alguna manera acabe, no continúe, ese es el problema. (GD1)

O cuando no se tiene claro el encaje procesal de la misma:

... la conclusión yo creo que la tenemos clara todos. Yo a pesar de todo sigo siendo partidario de la mediación (...) pero yo quiero que la misma tenga encaje en el proceso penal, que no se quede exclusivamente en perdón, la víctima, lo que son las buenas intenciones, sino que de alguna manera lo reflejemos.

Se trata de una cuestión de seguridad jurídica entre otras cosas, porque si no en cada sitio (...). (GD1)

Así pues, las posibles resistencias de los jueces y fiscales respecto a la mediación, por lo tanto, no tienen que ver con la mediación en sí, ya que cuando conocen directamente lo que supone y "experimentan", por así decirlo, sus efectos, se muestran muy partidarios de su desarrollo e implantación. De hecho, todos ellos insisten en que lo que antes era una realidad "ajena" a la cultura y la formación del juez, hoy día es algo conocido y asumido - sobre todo en las generaciones más jóvenes, por la formación inicial que actualmente reciben- pero en lo que sigue siendo necesario profundizar. Las reticencias son, si se quiere, de carácter técnico y "metodológico" y tienen que ver con la necesidad de proteger algunos de los principios básicos de la jurisdicción penal, como son el de presunción de inocencia y el de imparcialidad del juez.

De un lado, para jueces y fiscales una de las condiciones fundamentales para plantear la mediación penal en el proceso es que, de alguna manera, se reconozcan los hechos - aunque se discrepe en su calificación jurídica- ya que si no temen que resulte vulnerado el principio de presunción de inocencia. Temor que resulta infundado dado que el juez no puede alterar el principio de presunción de inocencia porque el infractor acuda a mediación. No es necesario reconocer la culpabilidad para entrar en 
mediación, y no por entrar en mediación te reconoces culpable: tu derecho a presunción de inocencia queda expedito. De hecho, tras los procesos de mediación hay una construcción colectiva de la realidad y del conflicto que distribuye y equilibra, en su caso, las responsabilidades.

Así por ejemplo, dice un juez:

... tenemos un procedimiento encorsetado, y tenemos que partir del principio de presunción de inocencia del reo; es decir, al final aplicaremos mediación en cuanto la persona sometida al procedimiento penal reconozca unos hechos porque, claro, si él niega los hechos no podemos ni entrar a mediación porque aplicaría el principio de presunción de inocencia. (...), si tú en instrucción quieres ir a medidas reparadoras de mediación y él está negando los hechos no hay mediación que quepa, porque si no presuponemos (...), porque si no estás vulnerando el principio de presunción de inocencia. Tienes que partir por lo menos de que se reconocen unos hechos, que luego se puede discrepar en la calificación de esos hechos, entender que está justificado. Pero si partimos de que él niega los hechos que se le imputan no cabe. (GD1)

De todas maneras, dado que la mediación se rige en todo caso por el principio de voluntariedad, también cabe pensar si incluso negando los hechos podría plantearse la posibilidad de una intervención restaurativa con el fin de "aclarar" lo sucedido. De hecho, algunos de los integrantes del grupo aseguraban que:

...si no reconoce los hechos yo no le puedo hacer pasar por un proceso de mediación, pero es que a lo mejor resulta que reconocer los hechos simplemente es planteárselo. (GD1)

Unido a ello, la otra gran preocupación de los jueces es cuidar y mantener la necesaria imparcialidad -y la apariencia de imparcialidad- exigible en el proceso: "Nosotros tenemos que estar fuera", dicen los jueces, "nosotros no podemos", "tenemos que externalizar"... Las peculiaridades de la jurisdicción penal hacen que el papel del juez no pueda ser el mismo que en otros ámbitos jurisdiccionales (civil, laboral...) donde el juzgador puede tener un rol más activo en el impulso de la acción mediadora. Aquí, insisten, la implicación es más problemática por cuando el juez puede verse "mediatizado" o "contaminado". Por eso suscitan dudas las experiencias de aquellos magistrados que "hacen" mediación penal o que al valorar la posibilidad de la misma acceden al material de instrucción, por lo que ello pueda afectar a la apariencia de imparcialidad, de acuerdo con la jurisprudencia constitucional. De ahí también que se insista en la importancia del papel de los fiscales, y en la posibilidad de que, a través de las instrucciones de Fiscalía, de su iniciativa y su liderazgo, pueda favorecerse el impulso de la acción mediadora y la necesaria homogeneidad en su implantación.

Con todo, los propios profesionales también señalan que para que la mediación penal restaurativa pueda tener lugar es necesario que, respetando esas garantías, cambie la cultura judicial. Es necesario, dicen, "cambiar la forma de entrar en sala" (GD1), fomentar la cultura de paz, el derecho colaborativo, cambiar la idea del proceso judicial como un juego de suma cero en el que el que llega al juzgado es para ganar o perder. Esta cuestión no afecta únicamente a jueces y fiscales, sino también a los abogados. Dice, por ejemplo, un abogado:

... mi objetivo como abogado es intentar defender los intereses de mi cliente; no ganar el pleito para mi cliente, sino defender sus intereses. Y sus intereses a veces se defienden en un pleito, pero otras veces no se defienden en un pleito. Esa es la cuestión. (GD2)

\section{2. ¿Autonomía y "privatización" del delito? ¿Qué delitos?}

Como se sabe, conceptualmente la mediación es una forma de diálogo en la que un tercero independiente e imparcial -el mediador- ayuda a que las partes puedan alcanzar por sí mismas un acuerdo. Como tal, la mediación no ofrece problemas en aquellos ámbitos -familiar, civil, laboral, mercantil...- donde las partes actúan 
autónomamente como "dueños", por así decirlo, de su problema. En el ámbito penal, sin embargo, la dificultad viene dada por la falta de autonomía de las partes para llevar el caso ante los tribunales cuando se trata de delitos públicos y por las peculiaridades del conflicto que es objeto de discusión - el delito, que no solo ofende a las partes, sino que vulnera bienes jurídicos considerados socialmente importantes (Estirado de Cabo 2008). Como se sabe, "en la justicia penal no hay partes, es que la víctima no es una parte" (GD1), sino un testigo cualificado del delito del que ha sido víctima. De hecho, lo que la mediación penal restaurativa pueda aportar es precisamente, aquello a lo que el proceso tradicional no llega: el reconocimiento y la participación de la víctima en la solución del conflicto que le afecta (Soleto 2017). Y es que el conflicto penal no es, por así decirlo, "propiedad" de las partes, sino que es dirigido y resuelto por el Estado a través de los operadores de la justicia penal. De ahí que una de las dudas que suscita la mediación penal, y que los operadores jurídicos manifiestan expresamente, tiene que ver con la posible privatización del proceso a través de la mediación:

Hablamos de la víctima, y a mí me parece fundamental, pero también soy escéptico a algunas cosas que yo en su momento oí acerca de las tendencias privatizadoras del derecho penal. Al fin y al cabo, no nos olvidemos que el derecho penal no tan solo tiene como propósito satisfacer a una persona concreta, como por ejemplo sería el derecho civil, sino también por ejemplo funciones de prevención general, funciones especiales, es decir, evitar no solo que la víctima siga sufriendo daño, o satisfacer sus necesidades subjetivas, sino también servir para impedir que ese delito se vuelva a cometer. (GD1)

Por eso, a la preocupación sobre la forma en la que debe desarrollarse la mediación, el papel de los operadores jurídicos y el alcance y efectos de la mediación (sea con acuerdo o sin él), ha de sumarse también la cuestión sobre los casos - los tipos de delitos- en los que la misma puede darse. "No todo es mediable", decíamos anteriormente. Eso significa que, por las circunstancias de las partes, no en todos los casos es posible intervenir restaurativamente o llegar a un acuerdo. Por ejemplo, de los expedientes de mediación penal intrajudicial analizados entre enero y septiembre de 2018 por la Asociación ¿Hablamos? en el marco del proyecto piloto desarrollado ese año, casi en el $75 \%$ casos se pudo comenzar la mediación. En el resto de los casos, ésta no pudo llevarse a cabo porque se retiró la denuncia (en un $40 \%$ de las ocasiones), porque no se pudo localizar al investigado ${ }^{7}(20 \%)$ o por deseo de la víctima en el $40 \%$ restante de los casos (Asociación ¿Hablamos? 2018). Ahora bien, salvada la voluntariedad y circunstancias de las partes, ¿hay casos en los que, en principio, ni siquiera debe intentarse?

Según los datos del proyecto piloto de la Asociación ¿Hablamos? de 2018, la mayoría de los casos derivados a mediación lo son de delitos contra la integridad física y la libertad; ambos suponen entre los dos más del $50 \%$ de los expedientes derivados, correspondiendo el resto a delitos contra el patrimonio, el honor o la intimidad. La tipicidad de los delitos derivados a mediación está muy vinculada a la existencia de una relación entre las partes (en más del $50 \%$ de los casos existía una relación previa de vecindad o familiar) en la que se produce algún enfrentamiento o pelea. En todos esos casos, la calificación otorgada a los delitos es leve (en el $90 \%$ de las ocasiones) o menos grave, observándose una cierta resistencia por parte de los juzgados a derivar casos con una tipificación o calificación más variada (Asociación ¿Hablamos? 2018). En el informe se reconoce que existe una cierta tradición o rutina en la tipología de delitos derivados a mediación que parece limitar que se abra el camino a otras tipologías delictivas (Asociación ¿Hablamos? 2019).

Hay quienes opinan que la mediación debe limitarse a los "delitos con víctima" y que sean semipúblicos (o cuando haya denuncia). Eso excluiría aquellos casos en los que

\footnotetext{
${ }^{7}$ En la Comunidad Autónoma de Aragón, la localización del investigado es tarea del mediador. Algo que incrementa su volumen de trabajo y para lo que no siempre cuenta con los medios necesarios.
} 
la víctima o perjudicado es "exclusivamente", por así decirlo, el Estado, la Administración, la Hacienda Pública, la comunidad....

Lo dejamos para los delitos que se persiguen por denuncia por ser semipúblicos, porque para los delitos públicos seguimos sin tener una solución. (GD1)

Pero también hay quienes piensan que la única limitación debe ser la que pone la ley - en los casos de violencia de género- e incluso en este caso tanto jueces y fiscales como abogados y mediadores manifiestan sus dudas sobre la justificación de la prohibición legal. Una cosa es que en determinados casos - por las circunstancias de la víctima- deban cuidarse más las condiciones en las que la mediación se lleve a cabo, o deban incrementarse las cautelas de los responsables procesales a la hora de derivar o impulsar una posible mediación penal, y otra cosa es que no pueda haber intervenciones restaurativas - sean o no mediación- en esos y otros casos graves (incluso en casos de terrorismo; cfr. Sáez Valcárcel 2011, Pascual 2013). No es el tipo de delito o la gravedad del hecho lo que debería condicionar el hecho de que se lleve a cabo la mediación, sino las posibilidades o no de alcanzar efectos restaurativos allí donde la respuesta penal tradicional no llega. Por ejemplo,

... a mí no se me ocurriría en un asesinato o en una agresión sexual plantearlo - dice una jueza. Pero (...) si la víctima te lo pide, no le puedes decir que no. (GD1)

De hecho, con los datos estadísticos de los que se dispone, y a pesar de las dificultades que evidentemente conlleva la intervención restaurativa cuando los delitos son más graves, el "éxito" de la mediación -si así puede decirse para referirnos a la posibilidad de iniciar un diálogo restaurativo e incluso alcanzar un acuerdo- no parece estar en función del tipo de delito y más parecería estar en función de otro tipo de variables como la relación entre las partes. ${ }^{8}$ Por eso, como afirma algunos de los intervinientes, si de lo que se trata es de atender las necesidades de la víctima y la responsabilidad del delincuente, "en la justicia restaurativa no hay límites" (GD1).

\subsection{Cultura social y mediación}

Otro de los condicionantes fundamentales de la mediación penal - y a la vez una de las dificultades o reticencias en su implantación y desarrollo- tiene que ver con la supuesta "cultura penal" de nuestra sociedad. Por un lado, según los profesionales que intervienen existe un amplio desconocimiento sobre la mediación penal, su alcance, etc., lo que lleva a desconfiar, al menos inicialmente, de su eficacia; o a no considerarla como una opción válida. Por otro, socialmente parece exigirse un derecho penal cada vez más amplio y represivo que dificulta las posibilidades restaurativas y con efecto a corto y medio plazo de la mediación. La percepción de los operadores jurídicos es la de que se ha expandido el derecho penal:

... ahora hay muchas conductas que antes no se perseguían, que no tenían encaje penal. (GD1)

Ambas tendencias hacen que se acuda cada vez más al Derecho en general, y al proceso penal en particular, para resolver conflictos que podrían encontrar otra respuesta por otras vías. Como destaca Varona $(2019,30)$, "hemos naturalizado la respuesta judicial penal". Se acude a los tribunales para resolver problemas familiares, de vecindad, confiando los efectos restauradores en la pena o sin plantearse la necesidad de una solución restaurativa, sino simplemente retributiva:

... hay cantidad de delitos leves, cantidad de hechos de familiares, de vecinos... que todos te piden una medida de alejamiento. Ahí ya estás creando un campo de cultivo para que se genere otro delito, ya de quebrantamiento de condena, de medida

\footnotetext{
${ }^{8}$ Según los datos de la Asociación ¿Hablamos? (2018) no parecer que el tipo de delito sea determinante para llegar a un acuerdo, y aunque tampoco hay evidencia estadística, la mayoría de mediaciones sin acuerdo han sido cuando las partes eran vecinos o familiares.
} 
cautelar... Que si llegan a un acuerdo en la mediación, pues yo creo que se consigue una pacificación social. (GD1)

... yo veo a la sociedad más agresiva, y más, más (...). Últimamente lo comentaba con el fiscal (...) que tengo en el juzgado: es que, a la mínima, una denuncia por coacciones (...), le tomas ofrecimiento de acciones, medida cautelar. Te piden automáticamente una medida de alejamiento (...). Si concediéramos todas las medidas de alejamiento que nos piden necesitaríamos calles para gente que fuera sola (...). (GD1)

Más aún, pareciera como si la reparación de la víctima pasara únicamente a través del castigo del delincuente, que lo único a lo que tiene derecho la víctima es a obtener una sentencia ejemplar:

Otra cosa con la que creo que la mediación se enfrenta, y es una pelea un poco difícil de librar, es (...) la tendencia social actual a plantear el proceso penal (...) como un castigo y como una búsqueda de una sentencia ejemplar (...) lo vemos en los medios de comunicación todos los días (...). La mediación va por un camino totalmente distinto. (GD2)

En ese sentido, todos los operadores (jueces y fiscales, abogados y mediadores) insisten en la necesaria labor pedagógica que hay que realizar: con los jueces, con los abogados, con las partes... fomentando la cultura de paz y el diálogo porque es lo que, al final, puede tener un mayor efecto preventivo de la delincuencia. Es claro que para que la mediación penal intrajudicial logre consolidarse es preciso difundir una cultura social restaurativa pero, en primer lugar, los operadores jurídicos deben conocer a fondo la filosofía restaurativa y estar convencidos de las posibilidades que ofrece la mediación penal como forma de resolver el conflicto que enfrenta a las partes, pero también como una herramienta que permite evitar y resolver conflictos extrajudicialmente a medio y largo plazo. Esta convicción por parte de las instituciones y de los operadores jurídicos y judiciales resultará esencial para asegurar que la llamada a la ciudadanía a mediar en sus conflictos encuentre un canal expedito, ágil y eficaz.

\subsection{La mediación penal intrajudicial: ¿una cuestión de "buena voluntad"?}

Tampoco cabe duda de la responsabilidad y el protagonismo de las administraciones públicas en el fomento de esa cultura y en el desarrollo e implantación de la mediación restaurativa en el proceso penal. Es algo obvio cuando se observa el desigual mapa de la implantación de la mediación penal en el Estado español. ${ }^{9}$ Como decíamos antes, a día de hoy la experiencia de todos los operadores profesionales es que la mediación penal intrajudicial es un asunto "de buena voluntad", caracterizada por "el buenismo y el voluntarismo" de unos cuantos:

Al final es una lotería, el que tiene suerte de coincidir en un juzgado que facilita el acceso a la mediación, tiene esa suerte, y el que no, no la tiene. (GD2)

El liderazgo, como suele decirse, conlleva indicar un horizonte y unos objetivos claros y poner y organizar los medios necesarios para alcanzarlos. En la mediación penal intrajudicial ambos elementos no parecen estar muy claros, a tenor de las opiniones de los participantes en los grupos de discusión. Y no es que falten experiencias a imitar, a nivel nacional y también internacional, que muestran el éxito de la mediación penal intrajudicial cuando las instituciones se ponen de acuerdo y apuestan por ella de forma consistente y prolongada en el tiempo. Faltan orientaciones claras, instrumentos adecuados, recursos... Lo que se hace queda al albur del interés personal del juez, el fiscal, los abogados, los mediadores... Dice, por ejemplo, uno de los operadores jurídicos participante en los grupos de discusión:

\footnotetext{
9 En 2009, según los datos del CGPJ, el número total de juzgados que hacía mediación penal era de 170, de los cuales el 70\% estaba en Cataluña y País Vasco y el 30\% restante se repartía entre Andalucía, Madrid, Castilla y León, Comunidad Valenciana, Navarra y, por último, Aragón (Sáez Rodríguez 2010, 2011).
} 
... no tenemos ningún tipo de... no nos facilitan nada, no nos facilitan la tarea; digamos que acabamos otra vez con ese buenismo de (...) a ver quién quiere hacer mediación, a ver qué es lo que damos este año de subvención para que podamos hacer más. Pues no. No tenemos unos instrumentos adecuados (...). Tenemos muchas leyes, tenemos muchos formularios, y no tenemos (...). (GD1)

Si las políticas públicas en materia de justicia suscitan dudas o reservas por la secular instrumentalización y la falta de medios, en el caso de la mediación todavía más:

- ¿Pero da votos invertir dinero en mediación penal de adultos?, ¿en la vía Nanclares? Eso no da votos nunca; ha quitado votos.

-En justicia, nada. (GD1)

Se podría decir que unas directrices poco claras sobre la mediación penal abocan al voluntarismo. Y es precisamente este voluntarismo una de las principales fuentes de incertidumbre de la mediación penal intrajudicial. Por un lado, por la tentación de los poderes públicos de empezar siempre de nuevo, en lugar de aprovechar lo alcanzado, aprender y consolidar de la experiencia. Dice por ejemplo uno de los participantes en el grupo de jueces y fiscales:

... si tenemos algo, lo que tenemos que hacer es convertirlo en algo consolidado, no puede ser que empecemos y volvamos para atrás. (GD1)

Por otro, por la volubilidad o en ocasiones la inconsistencia, por así decirlo, de tales políticas:

- Lo que no puede ser es que una persona haga mediación tres meses, luego no tengas subvención...

- O lo haga gratis. (GD1)

De ahí que todos los operadores implicados en los procesos de mediación insistan en la necesidad de reforzar el respaldo institucional, "y no de cualquier manera" (GD2).

\section{I ntegrar la justicia restaurativa en el proceso penal}

Es difícil poner puertas al mar. Y también parece que resulta complejo intentar encajar una filosofía restaurativa de resolución de conflictos que subyace a la mediación en la forma de actuación que propone la justicia penal. Y no solo es complejo porque tienen dinámicas y tiempos diferentes, sino que es complejo, sobre todo, porque la literatura existente recuerda que se llega a la propuesta de justicia restaurativa, precisamente por los límites de la propia justicia penal tradicional (Zehr 2002, 2012). Así las cosas, puede resultar incluso contradictorio intentar este encaje. De hecho, algunos de los participantes en el grupo de discusión reconocen que se acercaron a la mediación desde las limitaciones de la justicia penal:

...cuando tuve claro que todo lo que me aparecía encima de la mesa de mi despacho, yo no lo podía resolver en el juzgado, y que lo que no resolvía en el juzgado lo resolvía mediante la negociación, el acuerdo y tal, pues se llegaba a soluciones satisfactorias. (GD2)

Quizás lo importante es ser conscientes de que, como indica la Guía del CGPJ para la práctica de la mediación intrajudicial "utilizar la mediación en el ámbito judicial penal supone un cambio de cultura, tanto de la sociedad como de los profesionales que intervenimos en el sistema judicial. Hace falta devolver a la sociedad civil su responsabilidad de resolver el conflicto" (CGPJ 1990, 89).

\subsection{Encajar la mediación en las estructuras del proceso penal}

La principal dificultad para intentar ese complejo encaje de la mediación en el proceso penal procede del hecho de que la justicia restaurativa - y la mediación como una de sus herramientas más extendidas- se define por su informalidad y por la necesidad de adaptación a los casos y circunstancias de las personas implicadas. De hecho, Aguiló Regla $(2015,97)$ apunta que la mediación intrajudicial se ve como un posible 
"remedio a la excesiva rigidez del proceso judicial". Se trata de un punto de partida de la mediación que hace complicado que se pueda encajar en el rigor, la estructura, tiempos y formas de la justicia penal. En esa línea, indican que

una cosa es lo que nosotros queremos, lo que nosotros buscamos y otra cosa es lo que tenemos (...) tenemos un proceso penal que es el que es, con unos principios del proceso (...) que son radicalmente contrarios. (GD1)

Una de las cuestiones que suscitan más debate tiene que ver con el momento y los tiempos de la mediación, más dependientes de las propias partes, de su disponibilidad y necesidades, y los tiempos del proceso penal, más estructurados e impasibles. Consideran que el problema es

cómo acompasar los tiempos de mediación a los tiempos de proceso. El proceso judicial es un procedimiento con unos tiempos muy marcados (...) los tiempos del proceso penal no atienden nunca a la situación en que se encuentra la víctima y el responsable. (GD2)

Relacionado con la forma de entender el transcurso del tiempo en las distintas formas de resolver los conflictos, está la cuestión del momento procesal en el que debe o puede integrarse la mediación. De ahí, que una de las principales discusiones tenga que ver con el espacio y tiempo que debe tener la mediación, si previa al proceso, durante o, incluso, con posterioridad al mismo y a una sentencia firme. De hecho, ante las dudas que plantea ese momento procesal, los participantes en los grupos no la ven como otra forma de justicia posible y parecen decantarse en ocasiones por ubicar la mediación en una fase post procesal que permita resolver cuestiones que de otra forma no se resolverían. Indican que se trata de ver las opciones que ofrece el legislador y de ver las ventajas quizás "no en el momento a lo mejor del juicio, sino incluso después" (GD1). En realidad, se trata de que se atienda a la víctima y se resuelva el conflicto sin que la estructura judicial cambie. En esa línea, se apunta que un buen momento para pensar la mediación sería

después de la sentencia, de cara a que la víctima haya tenido una satisfacción más personal, más subjetiva, de cara a facilitar lo que comentabais, la ejecución de la eventual sentencia, yo creo que tendríamos que discurrir en esos ámbitos. (GD1)

No obstante, de forma más generalizada insisten en buscar una ubicación a la mediación en el proceso penal, conscientes de que, quizás, esa es la única manera de que llegue a consolidarse como mecanismo 'diferente' de solución de conflictos y de que los efectos restaurativos de las relaciones sociales, responsabilizadores y reparadores del daño se logran cuando el proceso de mediación es previo al juicio y las partes participan en la solución del conflicto. Otra de las razones para intentar integrar la mediación en el procedimiento tiene que ver, quizás, con la mentalidad "procesalista" de los operadores jurídicos, que son quienes deciden si el caso es susceptible de mediación o no, y que de alguna manera intentan encajar una forma de solución de conflicto "novedosa" en un esquema más conocido y que se apoya en principios asentados y no discutidos de proporcionalidad, legalidad, ius puniendi del estado... En ese sentido, destacan que "si no trasciende al proceso, al fiscal no le interesa" (GD1). Por ello entienden que, para el Fiscal, parece que el "premio" de pasar el caso a una reparación es similar al que obtienen con una conformidad:

... para trasladar a los compañeros, para intentar hacer un poco de pedagogía, tenemos que darles algo, decirles, mira, vamos a hacer este esfuerzo, pero vamos a tener el premio que el proceso va a acabar antes, que no vais a tener que calificarlo por los fiscales, que no vais a tener que hacer un escrito de calificación, que no vais a tener que ir a juicio. De alguna manera, el premio que tiene una conformidad. (GD1)

Ahora bien, cuando se piensa en las opciones que ofrece la legislación procesal, muchos operadores indican que no lo ven claro. No aprecian "en la Ley de Enjuiciamiento Criminal dónde está el engarce de ese cambio de calificación, por ejemplo, por el fiscal. En qué momento la víctima puede acudir al ministerio fiscal 
para decir 'esta solución me satisface', habría que cambiar la calificación o habría que pedir la pena que se está pidiendo" (GD1).

Algunos adelantan que la solución que ellos consideran posible para implantar adecuadamente la mediación restaurativa dentro del proceso penal es reconducir la mediación hacia la figura de la conformidad del investigado. Indican que

muchas veces lo que le puedes ofrecer es la posibilidad de transformación en diligencias urgentes y la conformidad con la reducción de un tercio, porque es lo único que nos da la Ley de Enjuiciamiento Criminal, aparte de la atenuante de reparación del daño. Es que no tenemos más, entonces tenemos que irlo encajando por ahí. (GD1)

Yo (...) en instrucción, y en delitos más graves como lesiones y delitos de robo, sí los he derivado a mediación y han dado resultados satisfactorios, y luego el procedimiento ha seguido, pero ya con atenuantes de reparación del daño, incluso se ha podido transformar en diligencias urgentes y beneficiarse de la rebaja del tercio (...). en estos casos (...) una vez que el infractor está conforme en derivarlo a mediación (...), te pones en contacto con la víctima y das aviso al fiscal, si el fiscal está conforme lo derivas y ya. Y ahí has metido al fiscal. (GD1)

... para que haya esa consecuencia penológica favorable que incite o fomente la mediación, tenemos la posibilidad de la transformación en diligencias urgentes con conformidad para la reducción de penas, en las penas que nos lo permiten, o de escritos de calificación conjunta (...) aparte de la reparación del daño como circunstancia atenuante. (GD1)

Otros plantean que, aunque ese sea un encaje posible, es preciso distinguir nítidamente la conformidad de la mediación. La identificación de ambas figuras puede acabar pervirtiendo la esencia de la mediación y anulando sus efectos restaurativos: la conformidad puede acabar entendiéndose como una especie de negociación (en el que tanto la participación y reparación de la víctima, como la responsabilidad del infractor, se diluyen) que no tiene que ver con la esencia restaurativa de la mediación. De hecho, Aguiló Regla $(2015,61)$ define la negociación como "una actividad en la que intervienen varios sujetos y que está orientada a alcanzar un acuerdo-decisión cuyo contenido es un intercambio". En tanto que la mediación intrajudicial, como indica el propio autor, "se considera un mecanismo adecuado, eficaz, para resolver los conflictos emocionales y de todo tipo que el proceso judicial no es capaz de gestionar de manera satisfactoria debido a su excesiva burocratización" (Aguiló Regla 2015, 97). Para el agresor se convierte entonces en la oportunidad de "comprar una atenuante" que aligere su carga penal y para la víctima en una posible forma impuesta de evitar las incomodidades del proceso. De ahí la necesidad de evitar la identificación entre mediación y conformidad o de condicionar el éxito de los procesos de mediación a la existencia de conformidades (o acuerdos). Sobre todo, porque entienden que "en el fondo la necesidad de la mediación es el fracaso de lo previsto, el fracaso de la conformidad" (GD1). En esa línea lo entienden mediadores y juristas:

La mediación yo creo que va un paso más allá de cuando hablamos de conformidad. En la conformidad al final lo que se busca es la pena mínima, y ya está (...). Con la mediación yo creo que tenemos que ir un paso más allá, es buscar ya, quizá a lo mejor, la justicia... (...) no sólo buscamos que sea beneficiado el investigado, también la otra parte (...) la mediación implica un paso más que la simple conformidad. (GD1)

... una mediación no ha de ser una conformidad, o sea una conformidad es otra cosa. Muchas veces es un arreglito que uno no sabe bien si el tío se ha conformado para que no le quiten el carné cuatro meses menos. (GD1)

De alguna manera, aunque vean en la conformidad la vía para integrar la mediación en el proceso penal, los operadores jurídicos son conscientes de que se trata de una conformidad especial porque "incorporaríamos un papel más participativo a la víctima". Y se advierte de que en ese caso "a lo mejor la víctima no quiere que se le 
reduzca la pena, sino que se le aumente". ${ }^{10}$ En esa línea, García Guillamón (2016, 202) insiste en que en los acuerdos de conformidad "no se tiene en consideración a la víctima (máxime si no está personada en la causa y por tanto no tiene ni abogado ni procurador). Sin embargo, en los acuerdos alcanzados en mediación penal, las necesidades de la víctima se verán plenamente satisfechas pues ella quien participa activamente en la resolución del conflicto mediado".

Por su carácter esencialmente pragmático, y con la preocupación por consolidar la institución de la mediación en el procedimiento judicial, los operadores jurídicos participantes en los grupos de discusión también debaten sobre las consecuencias reales de la mediación, esto es, en qué se traducen o han de traducirse los acuerdos - o no acuerdos- derivados de los procesos de mediación. Plantean dos soluciones: la atenuación de la pena o el perdón, previstos ambos en el Código Penal. La atenuación de la pena es la consecuencia prevista por el Código Penal (art. 21.5) cuando el culpable ha reparado el daño ocasionado a la víctima en cualquier momento del procedimiento pero siempre que se produzca antes de la celebración del juicio oral. De hecho, así lo ven los propios operadores jurídicos:

...el único engarce en el procedimiento penal, en cuanto a delitos públicos normales, es la atenuante de reparación del daño o luego en la ejecución, pues posibilidades dentro de los beneficios que admite el Código Penal.

También se plantea, si se dan las condiciones legales, la posibilidad de llevarlo a través del art. 130 Código Penal que regula la figura del perdón:

... entonces al final donde lo encajamos es por vía del perdón y del 130, extinción de la responsabilidad por perdón porque estamos hablando de coacciones, amenazas, etc. (...). Y decir, oye, vamos a resolver, y si es un tema donde está implicados también, pero no es privado, decir, mira no entramos en sala, hablo con ellos, lo resolvemos, y dice, aquí no ha venido nadie, sentencia absolutoria por falta de pruebas.

En todo caso, los participantes en los grupos de discusión no hacen mención expresa a las posibilidades que ofrece la reforma del Código Penal (LO 1/2015), en vigor desde julio del mismo año, a los acuerdos de mediación en la fase de ejecución de la condena. En ese sentido, el Código Penal hace referencia en su art. 84.1 al "cumplimiento del acuerdo alcanzado por las partes en virtud de mediación" como una de las condiciones que permiten suspender la ejecución de la pena inferior a dos años "cuando sea razonable esperar que su cumplimiento no sea necesario para evitar la comisión futura de nuevos delitos, siempre que se trate de un delincuente primario y se hayan satisfecho las responsabilidades civiles" (Cervelló 2016, 81). La propia autora entiende que esta mención a la mediación en el Código Penal "supone el respaldo legal a todos los programas de mediación que se están desarrollando en diversos Juzgados y Tribunales españoles y que venían trabajando sin ninguna cobertura legal expresa", obliga al legislador a regular la mediación y "especialmente el estatuto del mediador para configurar sus requisitos profesionales, su formación y su código deontológico" al tiempo que exige "coordinar la legislación penal con la procesal" (Cervelló 2016, 82).

\subsection{Protocolizar o no protocolizar: esa es la cuestión}

Ya habíamos avanzado que una de las cuestiones que está detrás de la exigencia de integrar la mediación en el proceso judicial tiene que ver con el logro de mayores niveles de seguridad jurídica. El proceso judicial exige el respeto de una serie de derechos y garantías que se consideran irrenunciables en el logro de un juicio justo y la mediación parece preferir una intervención más sustantiva y sostenible en la solución de conflictos y en la tarea de pacificación social, y una mayor flexibilidad

\footnotetext{
${ }^{10}$ Nos gustaría anotar que algunos autores han apuntado la idea de que los procesos restaurativos no solo deben estar orientados a satisfacer las necesidades de la víctima, sino también, de alguna manera, a transformarla cuando lo que manifiesta no resulta compatible con una filosofía restaurativa (Bennett 2007, 248).
} 
para adaptar los tiempos y procesos a las exigencias del caso a resolver y de los individuos implicados en el mismo. Integrar la mediación en el proceso penal lograría aunar los beneficios de ambos. Sin embargo, también es necesario repensar los perjuicios que puede generar la protocolización de los procesos restaurativos o, al menos, de la estandarización de los procesos de derivación de casos hacia una solución mediada. Se trata de una idea compartida por el CGPJ que ya en 1990 hacía referencia a "la necesaria unificación u homogeneización a nivel territorial de la implantación del procedimiento de mediación penal dentro del proceso penal vigente (...) con el objetivo de eliminar la actual heterogeneidad en las prácticas actuales, aunque con la flexibilidad necesaria en sus formas, pero respetando unos principios básicos de actuación" (CGPJ 1990, 91). Para ello proponía la firma y suscripción de un Acuerdo de implantación y Protocolo de actuación de programas de mediación penal intrajudicial tanto a nivel estatal como territorial. De hecho, desarrolla in extenso el protocolo a seguir en las distintas fases del proceso penal (CGPJ 1990, 93 ss).

Así pues, la cuestión sería determinar las razones para apostar por una mayor estandarización de la mediación. Los operadores jurídicos, de un lado, ponen sobre la mesa la necesidad de protocolizar los procesos de mediación, por una diversidad de razones. La primera de ellas es evitar el personalismo en la toma de decisiones sobre la derivación del caso a mediación. Pero también como una forma de verificar la calidad de los procesos de mediación, porque reconocen que, si no, los mediadores "lo hacen bien, pero no hay ningún control". Por eso es necesario "institucionalizar el procedimiento" (GD1), de la forma que sea.

Son conscientes de que el problema es conseguir el equilibrio entre la discrecionalidad necesaria para resolver el problema de forma individualizada y la exigencia de una mínima coherencia en los procesos que asegure la seguridad jurídica y la igualdad de los ciudadanos. Una institucionalización rígida de los procesos restaurativos puede acabar con la filosofía de la justicia restaurativa que debe estar subyacente y que exige estar atento a las circunstancias del caso que se intenta resolver y a los límites de la propia mediación. Así resume Aguiló $(2015,128)$ esta idea cuando destaca que "en la mediación, la creatividad y la virtud del mediador tienen un protagonismo muy superior a la del protocolo de actuación". De hecho, en ocasiones se reprocha a los mediadores que sean conservadores y que permanezcan en la zona de confort, cuando lo que requiere una buena solución del conflicto es que sea creativa para adaptarse a las circunstancias y que intente ser transformativa (GD2). Al igual que hace Lederach $(2005,39)$, que invita a tomar riesgos para lograr la paz: "la construcción de la paz es un viaje guiado por la imaginación del riesgo". Es por ello por lo que, a la vez que piden una mayor regulación legal, muestran sus reticencias a una hiperregulación o legalización minuciosa de la mediación:

... lo primero sería que hubiera cobertura legal un poquito más amplia, aunque no amplíen mucho, porque cuando amplían mucho nos recortan por otros lados. (GD1)

... la falta de legislar y de concretar tanto, tanto, tanto, pues nos viene bien. (GD2)

Relacionada con las razones para protocolizar está la discusión sobre qué debe ser regulado. De hecho, se plantea la necesidad de estandarizar, si no los procesos, al menos las condiciones de derivación del caso a mediación y la información a las partes sobre los elementos esenciales del mismo (proceso, partes, qué se espera de ellos, qué pueden esperar de la mediación...). Esa exigencia hará que no se haga depender la derivación de la buena voluntad de las personas, de su mayor o menor conocimiento de la mediación, o de su mayor o menor confianza en la mediación como método de solución de conflictos.

Si realmente tenemos un servicio serio, también es más fácil establecer criterios consolidados. Ya no depende tanto del juez, del fiscal, del letrado, no, no, es que ya, oye mira, esto se hace así, pasa por esta vía y tenemos estos criterios. (GD1) 
Con protocolos o sin ellos, también les da seguridad y mayor confianza en los procesos de mediación el hecho de que sean las instancias judiciales las que controlen la derivación o no de casos hacia una solución mediada y, en ese sentido, proponen que asuma ese rol la oficina judicial. Consideran que quizás una de las razones por las que la mediación no ha dado un paso más es porque se externaliza y el sector jurídico parece que sigue siendo reticente a aceptar que la solución de los conflictos penales salga de su ámbito de control. Consideran que

a lo mejor, si estuviera todo dentro de la oficina judicial sería todo mucho más sencillo. (GD1)

Eso no quiere necesariamente decir que los mediadores tengan que ser funcionarios; o que sean éstos - los funcionarios judiciales- quienes deban asumir las funciones mediadoras. Al contrario, los intervinientes en los grupos de discusión tienen claro que los procesos de mediación propiamente dichos no los pueden realizar los operadores jurídicos, por no ser su función ni tener las habilidades ni competencias para ello o, como se apuntaba con anterioridad, porque puede interferir en su imparcialidad. Pero insisten en la necesidad de integrar y coordinar mejor los recursos en un servicio y en que ellos deberían controlar las derivaciones:

No me refería a que se externalizaran (...) a los mediadores que evidentemente no pueden ser los funcionarios de la administración de justicia, sino que se instara, que dentro de la oficina judicial haya un servicio dónde puedas derivar a las víctimas para que les informen, la sesión informativa, para que les expliquen qué ventajas se pueden obtener de la mediación, y que también esa misma oficina, pues vele por la garantía y la calidad de los mediadores. Y es que ahora estamos un poco en, por lo que decimos, el buenismo y el voluntarismo. (GD1)

\section{Propuestas para mejorar la credibilidad de la mediación penal intraj udicial}

La mediación sienta (o debería sentar) sus bases en la justicia restaurativa. Y ésta se mueve entre la fe incondicional de quienes han experimentado y verificado que funciona en la resolución de conflictos a corto y medio plazo, y la desconfianza de quienes identifican la mediación con la negociación, alertan de una privatización de la justicia que se califica de informal o no ven claro cómo favorecer la igualdad de los ciudadanos a través de una justicia adaptada a cada caso y a las partes implicadas en el mismo. Ante esas dudas, prefieren la seguridad jurídica que parecen ofrecer los procesos más estandarizados de la justicia penal tradicional, dirigida por profesionales que cuentan con una formación más reglada. De alguna manera le exigen a la mediación una serie de garantías para que lo que se ha logrado con la justicia penal clásica no se venga abajo con un modelo que arranca muy irregularmente en el marco de la justicia penal española.

Los profesionales entrevistados mediante el grupo de discusión plantearon varias cuestiones a mejorar para lograr consolidar la mediación penal intrajudicial como una opción válida de solución de los conflictos que surgen a partir de la comisión de delitos. Entre ellas, se plantea la necesidad de exigir garantías de que la misma la realiza un mediador profesional y de que se exigen unos mínimos formativos que determinen quién está capacitado para mediar. Además, se cuestionan cuáles deben ser los resultados de la mediación ya que en algunos casos se suele exigir la materialización en algún tipo de acuerdo, cuando en realidad los principales modelos de justicia restaurativa apuestan por considerar como resultado la apertura del diálogo entre las partes. Detrás de todo también se encuentran las reticencias profesionales sobre quién debe hacer qué en la mediación y, de forma más genérica, la oposición entre juristas y mediadores a la hora de resolver conflictos penales.

\subsection{Profesionalizar la mediación penal intrajudicial: ¿qué es un buen facilitador?}

Una de las reticencias para tomar en serio la mediación penal intrajudicial tiene que ver con la sensación de que no queda claro quién debe realizar la mediación, ni qué 
formación es precisa para ser mediador y hacer mediación "de calidad". Por ello, una de las propuestas para afianzar la mediación en Aragón (como en otros contextos) y darle una mayor credibilidad sería apostar por la profesionalización de la mediación que para algunos autores es la última fase de la institucionalización de la mediación (Faget 2006, 157). Además, parece requerirse que sea la Administración del Estado la que establezca unos mínimos - en conocimientos, en créditos, en competencias y habilidades- para poder ejercer la mediación de forma profesional.

... a base de voluntariado, de mucha ilusión, pues claro, mucha ilusión, a veces tampoco lleva a hacer un buen trabajo profesional. (GD2)

No garantiza que haya unos estándares mínimos de calidad. (GD2)

La cuestión nuclear aquí es qué entendemos por "profesionalización". ${ }^{11}$ De alguna manera, en paralelo a esa cuestión está la que parece oponer profesionalización y voluntariado. Sobre este tema se pueden plantear varias cuestiones interrelacionadas. Una de ellas tiene que ver con el hecho de que, si la mediación estuviera más institucionalizada en Aragón, quizás no sería necesario hablar de voluntariado en la mediación porque serían profesionales, integrados o no en la Administración de Justicia, quienes desarrollarían de forma constante su trabajo de mediadores. Así pues, parece que es la difícil e incompleta consolidación de la mediación la justicia penal aragonesa la que acaba convirtiendo a los mediadores en voluntarios. La falta de impulso institucional constante y sostenido a la mediación penal intrajudicial hace que el trabajo se desarrolle en los límites de lo judicial de forma voluntaria o casi. Parecería con ello que lo profesional se opone a lo voluntario. Pero no siempre es así. La profesionalidad no depende de la vinculación laboral o de la retribución. La diferencia real no está entre mediación profesional o mediación "voluntaria"; toda mediación es o ha de ser profesional en el sentido de estar dotada de unos recursos suficientes (personales, de formación y materiales), independientemente de quien la lleva a cabo. De ahí que la diferencia ha de hacerse más bien entre mediación con recursos suficientes versus mediación con medios escasos. Dicho con otras palabras: el problema de la "voluntariedad" de la mediación en Aragón no reside en el perfil de los mediadores ni en la práctica que llevan a cabo, sino en la falta de reconocimiento y dotación de recursos por parte de la Administración.

Además, hay una confusión que parece generalizada a la hora de definir el voluntariado que tiende a identificarse con un tipo de trabajo no remunerado, por supuesto voluntario, que se apoya en la buena voluntad de las personas y no cualificado. Hay que precisar que existe voluntariado en diversos ámbitos de la vida social que exigen una muy distinta cualificación (orientar a los visitantes de una ciudad, apoyo escolar a niños y niñas con necesidades especiales, o asesoramiento jurídico a través de las clínicas jurídicas, entre otras). La realización de mediaciones penales, por la complejidad de la tarea y por la implicación de derechos y libertades de los ciudadanos que supone, exige una cualificación importante previa. No basta con tener la voluntad de ser mediador para poder serlo. Por ello, alguna de las

\footnotetext{
${ }^{11}$ Generalmente tiende a identificarse el trabajo voluntario con la gratuidad y la profesionalización con la retribución económica. No cabe duda de que ese es un elemento a considerar y tener en cuenta; pero no es el principal o más importante. De hecho, la retribución en las profesiones tiene sentido para garantizar la especialización y la autonomía necesaria para el desempeño de una tarea que se considera esencial para la comunidad. Pero cuando hablamos de profesionalización el rasgo central es el reconocimiento social y técnico que supone el desempeño de una práctica, y que implica no solo la adquisición de un conjunto de conocimientos y habilidades específicas (habitualmente a través de la acreditación a través de un título), sino también de una cultura profesional, modelos de excelencia e incluso de un ethos profesional. No son pocas las implicaciones -y los riesgos- que conlleva el proceso de profesionalización, relacionadas con la posible burocratización de las actividades, la existencia de un monopolio de la actividad, etc. (vid., entre otros, González Anleo 1994, Hortal 2004). Baste con advertir que "profesionalización" no es sinónimo de "funcionarización"; que, por el contrario, la funcionarización de una actividad puede redundar en una mayor burocratización de la misma y que en cualquier caso el reto principal radica en la definición del proceso de reconocimiento de las competencias y la dotación de los recursos necesarios para el ejercicio autónomo de esa actividad en condiciones de calidad.
} 
mediadoras participantes en el grupo de discusión defiende que es posible un voluntariado profesional:

... no estoy colegiada en ningún colegio profesional, y yo me siento profesionalizada, soy voluntaria pero profesional. (GD2)

En ese sentido, dada la confusión que existe y la tendencia a valorar todas las actividades de voluntariado por igual, positivamente por lo que de buena voluntad y generosidad supone, pero negativamente en cuanto lo entiende como una tarea menor, se exige el

reconocimiento del trabajo de mediador (...). Cuando digo profesional no estoy pensando en ningún título, pero que es un trabajo, que además debe compensarse económicamente, debe ser retribuido, como es lógico, ¿verdad? Mientras eso no sea así, yo creo que es difícil que podamos avanzar en el futuro. (GD2)

La cuestión principal tiene que ver con la formación necesaria (el reconocimiento de los conocimientos y la competencia técnicas) para considerar "profesional" a un mediador. Está claro para todos que es necesario tener un conocimiento del derecho penal y del proceso en el que se va a integrar la mediación, para conocer las consecuencias penales de la misma. También deberán tener un conocimiento sobre los principios y objetivos de la justicia restaurativa y conocer sus procesos principales (Martínez Camps 2016, 226). Más complejo es saber cómo adquirir las competencias necesarias para poder mediar entre las partes. Los autores hacen referencia a las habilidades de la escucha activa, la empatía, la asertividad, la imparcialidad, neutralidad, la creatividad, la capacidad de mirar en positivo las diversas situaciones que se vayan a producir, el lenguaje no verbal, la gestión del silencio, entre otros (Sánchez Álvarez 2008, Martínez Camps 2016, 11, García Guillamón 2016, 206). Dada la amplia gama de conocimientos necesarios para facilitar una buena mediación, la diversidad de formación y su calidad parecen muy diferentes. Destacan por ello que

es muy importante homogeneizar un poco el conocimiento. Porque al título de mediador, hoy en día, se puede llegar por diferentes caminos, y algunos son más laboriosos que otros (...). Porque es verdad que, en algunos casos, pues hay que hacer un importante esfuerzo para recibir formación porque, pues porque allí dónde vas a obtener el título pues así lo plantean, así lo exigen, y a la larga es favorable pues porque de verdad aprendes más, y es verdad también que hay otras maneras de obtener el título que (...) dejan bastante que desear (...), yo creo que la homogeneización de los conocimientos sí que corresponde a la administración. (GD2)

En todo caso, parece claro que la formación debe ser multidisciplinar:

La visión de no solo una formación base en un sector, sino esa amplitud, que es lo que permite acompañar a las partes también a posicionarse desde diferentes partes, a trabajar el tema emocional. (GD2)

Pero añaden que junto a esa formación integral y multidisciplinar es preciso un cierto talante, una cierta actitud ante el conflicto y la forma de entenderlo y abordarlo de forma holística, y ante las personas. Algo que va en la línea de lo que plantea Lederach $(2005,35)$ cuando asegura que la construcción de la paz exige "experimentar, prever y generar una red de relaciones". Es algo que es válido tanto para juristas como para mediadores y que permite romper con los estereotipos de quién puede hacer qué:

... hay que tener un cierto talante mediador (...) y diría, incluso, un poco un talante conciliador. Esto en nuestra profesión se ve más, es decir, normalmente quien se aproxima a la mediación desde el derecho, se aproxima quien tiene, pues yo diría que aversión al pleito, porque todos sabemos que aversión no tiene nadie, pero también quien es consciente de que el pleito no lo resuelve todo y que en muchas ocasiones el pleito no sirve. (GD2)

... pero, hombre, es que un abogado va a manejar a lo mejor mal las emociones de las personas en mediación, o al revés, el estereotipo contrario, un psicólogo no va a negociar para llegar a acuerdos concretos. A ver, es que yo creo que esos son 
estereotipos; a mí, lo que en mediación, yo creo que, para un buen mediador, es que le gusten las personas, que te gusten las personas. (GD2)

También tienen claro que para ser un buen profesional es preciso mediar. La experiencia y la práctica reflexiva (o las "tablas") en la solución de conflictos a través de la mediación es la mejor manera de llegar a ser un buen profesional.

\section{2. ¿A qué aspira la mediación intrajudicial? ¿Cuándo estamos ante una mediación exitosa?}

También se ha considerado que para mejorar la credibilidad de la mediación penal intrajudicial debe quedar claro qué es lo que se pretende y qué es lo que logra efectivamente. Sobre esa cuestión hay que decir que hablar de la justicia restaurativa que está en la base de la mediación no es hablar de una sola filosofía, sino de varias que se han sintetizado por J ohnstone y Van Ness $(2007,9-16)$ en tres modelos. Esos modelos se distinguen en función de cuál es el resultado que se espera de los procesos restaurativos, que es lo que permite calificar una práctica de restaurativa o no. Más precisamente, distingue entre el modelo reparador, el del proceso y el de pacificación social. En primer lugar, el modelo de la reparación se centra en el logro de un acuerdo de reparación y en la reparación efectiva de los daños y perjuicios generados por el delito. De manera que la reparación del daño causado está en la esencia de la justicia restaurativa y de sus herramientas y si no hay reparación no se puede considerar que haya habido justicia restaurativa. Para otros autores, la justicia restaurativa es un proceso que permite abrir el diálogo entre las partes para discutir sobre lo ocurrido y pensar en común en la forma más significativa para reparar el daño causado. Se entiende que el propio proceso de diálogo orientado por un facilitador y basado en los principios de respeto y honestidad son ya un primer paso para resolver los posibles conflictos existentes y futuros y, en sí, un resultado válido. ${ }^{12}$ Por último, están quienes ven la justicia restaurativa como un objetivo a medio o largo plazo que se logrará cuando se consiga pacificar la sociedad y la forma de resolver los conflictos.

Sobre esta cuestión, los grupos de discusión muestran una cierta discrepancia entre los juristas y los mediadores (al margen de que éstos sean o no juristas de formación o ejerzan también de abogados). De un lado, los operadores jurídicos (jueces, fiscales o letrados de la administración), desde una perspectiva más pragmática, pensando en cómo consolidar la mediación y en convencer a los compañeros reacios a la mediación, consideran que es preciso ofrecer algo, un resultado, un acta de mediación. De otro lado, el grupo de los mediadores parecen atender más a una idea de justicia procedimental y aseguran que el propio proceso de poner a hablar a las partes ya es un logro, aunque no haya terminado con un acuerdo de mediación. Destacan como mágico ese momento en que "al final esas miradas se encuentran" (GD2) porque entienden que ese es el primer paso para que puedan hablar e intenten resolver los conflictos que tienen o que puedan tener en el futuro. De hecho, destacan que a veces no ha habido un acta de mediación "pero luego resulta que en el juzgado sí que se ha llegado y eso no ha sido (...) se facilita la comunicación y el diálogo" (GD2). Por ello aseguran que resulta limitado hablar

de los acuerdos y los tiempos sobre todo cuando hablamos en tema judicial, que estamos muy limitados (...), la esencia de poder aplicar una mediación más transformativa que apliquen otros métodos que no sean solo el llegar al acuerdo por llegar al acuerdo, sino que ayude también a las partes a restaurar más esas relaciones, sobre todo cuando estamos hablando de relaciones que se van a mantener en el tiempo. (GD2)

\footnotetext{
12 Pranis (2007) hace referencia a una diversidad de valores restaurativos en el proceso. Entre otros, se refiere a que el proceso restaurativo sea igualitario, que integre a todas las partes, que ofrezca un entorno seguro física y emocionalmente a las partes, que sea un proceso claro y comprensible, que genere la curación del daño, que sea voluntario, que condene el comportamiento, que ofrezca oportunidades de aprender, que recompense el comportamiento positivo...
} 
En quienes ya ven en la apertura del proceso de diálogo de la mediación un éxito se percibe un indicio de modelo transformativo que apuesta por un objetivo a más largo plazo: el de lograr la pacificación del conflicto primero y luego la pacificación social, humanizar los procesos de solución de conflictos devolviendo a las partes el protagonismo para implicarse en su resolución y en la reparación del daño. De hecho, se centran en esa idea de que para las partes esa apertura del diálogo ya ha merecido la pena:

El objetivo no es el acuerdo, el objetivo es esa pacificación en el conflicto y finalmente si se llega eso a plasmar en un acuerdo pues perfecto, pero si no ya es mucho (...) el número cuantitativo finalmente de acuerdos igual no es el que en determinados estadios debería contar, pero para nosotros nos sirve porque nos están haciendo el feedback desde juzgados, que a las partes y a las personas que allí aparecen les vale. (GD2)

... instrumento de pacificación, en el sentido de que va más allá del proceso penal tradicional, y del concepto de culpa sobre el que gira todo el proceso penal. (GD2)

Es beneficiar a nivel social y humanizar lo que a veces se deshumaniza y se deslegitima (...), devolver esa participación activa a los que verdaderamente importan que son las partes. (GD2)

Al margen de cuáles sean las percepciones de operadores jurídicos y mediadores, lo cierto es que para consolidar la mediación penal intrajudicial es preciso determinar una política pública clara en el ámbito de la justicia penal. La tendencia de la clase política, que parece verse obligada a ofrecer resultados tangibles y fácilmente mensurables ante la opinión pública, parece preferir la financiación de las mediaciones solo cuando se llega a un acuerdo y pagar simbólicamente aquéllas en las que no se logra por una diversidad de razones. Sin embargo, los propios participantes en los grupos de discusión son conscientes de que, en ocasiones, aunque no se llegue a un acuerdo, sin embargo, se consigue un acercamiento de las partes que facilita el acuerdo posterior en vía judicial o que mejora su capacidad para resolver los posteriores conflictos de una manera dialogada. Se trata de resultados que deberían ser tenidos en cuenta por su valía social en la construcción de una sociedad pacificada, pero que exigen mecanismos de medida diferentes y específicos.

\subsection{Las reticencias entre profesionales (abogados y mediadores): ¿de quién es} la mediación?

¿Quién puede mediar mejor, el que conoce el procedimiento en el que se integra la mediación, o quien tiene las herramientas y habilidades para abrir la comunicación entre dos personas? Es uno de los dilemas que atraviesa la implantación de la mediación penal intrajudicial y que, aparentemente, sigue sin resolverse. Como recuerda Aguiló $(2015,98)$, "parece que la mediación no fuera cosa de juristas, en general, y menos aún de abogados en particular". De un lado, los juristas parecen conceder una mayor importancia al marco jurídico y, en consecuencia, exigen que los mediadores conozcan el proceso penal:

Yo no me he encontrado a ningún experto en derecho penal haciendo funciones de mediación (GD1)

Algo que indica una cierta jerarquización en la consideración de quien aplica el derecho por encima de quien realiza funciones de mediación. Aunque tienen claro que los mediadores no tienen por qué ser expertos en derecho penal, ni tienen por qué ser los propios jueces quienes realicen funciones de mediación:

La mediación yo creo que ha de ser ajena, porque es la participación de la sociedad, es la situación de la víctima y es la situación de una persona que entiende, que puede entender que ha cometido un hecho delictivo, que ha causado un daño, sobre todo yo ya no estoy tanto en el resarcimiento económico sino en el resarcimiento moral de las víctimas (...); entiendo que ha de ser una persona que viva en la sociedad o que esté, yo entiendo más tipo psicológico, más ese tipo de persona o una visión diferente de lo que es decir yo aplico el tipo penal que yo aplico al caso concreto (...); 
ese trabajo a mí no me lo pueden pedir porque yo no puedo, y el juzgado, yo entiendo que los funcionarios del juzgado no pueden, no están preparados, no tienen esa capacitación para realizar esa tarea. Sino que ha de ser en otro orden de conocimientos diferentes de lo que es el derecho penal. (GD1)

Desde otra perspectiva, los abogados también se oponen y muestran reticencias a la mediación porque entienden que esa, la de mediación, ya es una tarea suya, que han realizado tradicionalmente en sus despachos profesionales. Aunque quizás esa apropiación proceda de una confusión entre la mediación y la negociación a la que están más acostumbrados en sus despachos de abogados porque "asumen que negociar en nombre y representación de su cliente es uno de sus roles profesionales centrales $(. .$.$) ; ¿qué sentido tiene - se preguntan muchos abogados y con razón- que$ un profesional de la negociación, como es el caso, tenga que negociar con un 'mediador de por medio'?" (Aguiló 2015, 98). Se asegura que

\begin{abstract}
... [I] os abogados de la defensa eran muy contrarios, eran absolutamente contrarios porque sentían como que la función era suya. Se sentían totalmente suplantados (...), ¿por qué va a tener que estar aquí nadie indagando sobre si he hecho o no hecho?, ya hablaré yo con el fiscal cuando llegue el momento. (GD1)
\end{abstract}

Una propuesta por parte de los propios mediadores para romper esa oposición por parte de los abogados iría en la línea de hacer que éstos acudieran a la primera entrevista. Es importante que el abogado comprenda la labor que tiene cada uno y las entienda como tareas complementarias, no opuestas. De hecho,

... el desconocimiento que la profesión tiene de la mediación es muy importante y la resistencia, a veces, insalvable. (GD2)

... es una de las maneras de traértelo a tu campo. Ven a la primera entrevista, a la primera parte, donde explicamos el proceso, las consecuencias, qué vamos a trabajar y cómo lo vamos a hacer, y en ese momento sí que facilita (...) la habilidad es intentar que se convierta en un aliado nuestro y que seamos transparentes con él, claro. (GD2)

También aparece en los grupos esa idea de que las resistencias de los abogados a hablar abiertamente de la mediación tienen un trasfondo económico porque entienden que la solución del caso mediante mediación supone un perjuicio económico para los abogados. Como resume muy bien Aguiló $(2015,98)$ para los abogados "todo conflicto mediado (...) es un conflicto no litigado". Entienden que la implantación de la mediación supone "quitar trabajo a la abogacía" (GD2).

Los propios compañeros iban obligados a la mediación porque la jueza (...), decían si sale la mediación, si sale con un acuerdo, voy a perder 4.000 euros (...), están deseando que no salga la mediación. (GD2)

Por ello, lo que puede acabar ocurriendo es que en algunos casos los propios abogados obstaculicen la puesta en marcha de la mediación temerosos de verse suplantados profesionalmente: "Muchas veces ya no es solo no estar conforme con la mediación, es muchas veces poner palos en las ruedas" (GD2).

\title{
6. Conclusiones
}

Las discusiones emergentes en los grupos de discusión realizados nos han permitido vislumbrar que frente a una filosofía de solución de conflictos que se pretende global y consolidada en diferentes contextos y en entornos diversos (delincuencia juvenil, conflictos vecinales, bélicos, culturales...) como es la justicia restaurativa, aparecen una serie de resistencias. Algunas, si no globales, sí son muy generalizadas si tenemos en cuenta las investigaciones realizadas y la literatura existente sobre justicia restaurativa y mediación penal. Otras son mucho más particulares, derivadas de la idiosincrasia y tradición de un determinado entorno. En todo caso, las reticencias generales siempre presentan tintes particularistas. Veámoslo.

Una primera cuestión que observamos cuando atendemos a las palabras de los participantes en los grupos de discusión es esa oposición entre un planteamiento 
ideológico y otro más técnico-procesal de la mediación. De un lado, predomina un planteamiento ideológico entre los mediadores profesionales que se centran en los aspectos emocionales de la misma cuando realiza los fines de la justicia restaurativa: responsabilizar al agresor y, sobre todo, reparar el daño causado a las víctimas y atender a las necesidades que quedan descuidadas en el proceso judicial. Al tiempo que prefieren evidenciar el éxito que supone abrir un proceso de diálogo entre las partes, al margen de que se llegue finalmente o no a un acuerdo. De otro lado, un planteamiento más procesal (o burocrático), preferente entre los operadores jurídicos, se centra en los mecanismos que permitan integrar la mediación en las estructuras y tiempos judiciales, en buscar un resultado mensurable de alguna manera (como podría ser un acuerdo de mediación), en encajar la mediación en las estructuras conocidas que no alteren la zona de confort judicial. Esta puede ser a menudo la perspectiva que inspira la orientación de las políticas públicas en esta materia, más preocupadas por el número de conformidades o acuerdos alcanzados que por las condiciones y los procesos de diálogo iniciados, lo que puede convertir a la mediación penal intrajudicial más en un mecanismo de solución de conflictos que mitigue los problemas del sistema penal, que en una herramienta de justicia restaurativa, que contribuya a reparar el delito y a pacificar las relaciones sociales. Según en qué lugar del espectro de las formas de entender la mediación nos ubiquemos, valoraremos la mediación como exitosa en el inicio del diálogo o en el logro de un acuerdo. Es evidente que el objeto de medida nos exigirá adaptar las herramientas. No hacerlo y permanecer en una medida de la mediación en función del acuerdo logrado genera un riesgo de que se pervierta la propia mediación en la que se "fuerce" el acuerdo para que éste sea contabilizado.

También resulta una preocupación generalizada la de la protocolización o no de la mediación. Se es consciente de que una cierta estructura puede dar más seguridad, pero demasiada estructura y un marco legal muy rígido puede acabar con el espíritu de la justicia restaurativa que se adapta al caso y sus protagonistas. Sin embargo, parece tener tintes más locales la concreción de qué se debe protocolizar o qué debe permanecer más discrecional. Así, los operadores jurídicos y los mediadores participantes en los grupos entienden que lo que se deben estandarizar son los procesos de derivación de mediación o aquéllos de información a las partes sobre las condiciones e implicaciones de la mediación, pero tienen claro que los procesos de mediación en sí son difícilmente protocolizables si aspiran a mantener su capacidad para adaptarse al caso a resolver. Puede resultar de interés cotejar el protocolo de coordinación interinstitucional para el Servicio de Justicia restaurativa en Euskadi (Departamento de Trabajo y Justicia del Gobierno Vasco 2019).

Una de las dudas de la mediación, y quizás una clave para comprender la azarosa implantación de la mediación en la justicia penal, está tanto en la definición de qué es una buena mediación como de quién es o puede ser un buen mediador. Desde una perspectiva general, cada autor destaca unos conocimientos, competencias y habilidades a desarrollar y potenciar por el mediador. A nivel más local se antepone la escasa implicación institucional en la definición de las competencias y conocimientos necesarios para serlo y, en consecuencia, la disparidad en los cursos y talleres que dan acceso al título de facilitador. Pero también queda claro que, en este caso, dada la importancia de la relación personal y profesional que se establece entre el mediador y las partes, la técnica no lo es todo. Se destaca la importancia de cuestiones difíciles de "aprender" en un curso como es la experiencia vital, las tablas que dan las mediaciones realizadas y el talante ante las personas y ante el propio conflicto. Se diría que esa preocupación por un talante restaurativo y reparador es global.

Algo muy general entre los impulsores de la justicia restaurativa, sobre todos en los orígenes, era el enfrentamiento entre una justicia penal (retributiva) "mala" frente a una justicia restaurativa "buena" (Daly 2002). Era una tensión que permitía mitificar los dos modelos de justicia que, por ello mismo, no dejaban de ser sino modelos. Los participantes en los grupos no ven tan clara la distinción entre ambas justicias, la 
retributiva y la restaurativa. Son conscientes de los límites que tiene el proceso penal a la hora de llegar a reparar de manera adecuada y constructiva a la víctima o de hacer participar a las partes en la búsqueda de una solución al conflicto generado por el delito. Sin embargo, también asumen las ventajas que tiene una justicia penal que cuente con todos derechos y garantías procesales y realice los principios ilustrados que están en su origen. Por ello, la tensión que evidencian es más bien cómo integrar la mediación en el marco estrecho de la mediación, cómo estandarizarla, siendo conscientes de que esos encorsetamientos pueden acabar con la flexibilidad y la creatividad que exige una mediación que aspire a adaptarse a las necesidades y disponibilidad de las partes.

\section{Referencias}

Aguiló Regla, J., 2015. El arte de la mediación: Argumentación, negociación y mediación. Madrid: Trotta.

Asociación ¿Hablamos?, 2018. Informe estadístico del proyecto piloto de mediación penal. Octubre. Zaragoza: Asociación ¿Hablamos?

Asociación ¿Hablamos?, 2019. La mediación penal intrajudicial en Aragón (20072019). La mediación penal intrajudicial como herramienta de justicia restaurativa. Experiencia y perspectivas de futuro. Zaragoza: Asociación ¿Hablamos?

Bennett, C., 2007. Satisfying the needs and interests of victims. En: G. Johnstone y D.W. Van Ness, eds., Handbook of Restorative Justice. Cullompton: Willan, pp. 247-264.

Cervelló Donderis, V., 2016. La mediación en el sistema penal español. En: V. Cervelló Donderis, ed., Cuestiones prácticas para la aplicación de la mediación penal. Valencia: Tirant lo Blanch, pp. 69-102.

Consejo General del Poder Judicial, 1990. Guía para la práctica de la mediación intrajudicial [en línea]. Madrid: CGPJ, Gabinete Técnico. Disponible en: http://www. poderjudicial.es/cgpj/es/Temas/Mediacion/Guia-para-la-practicade-la-Mediacion-Intrajudicial/ [Con acceso el 30 de octubre de 2019].

Daly, K., 2002. Restorative justice: the real story. Punishment and Society [en línea], 4, pp. 55-79. Disponible en: https://doi.org/10.1177/14624740222228464 [Con acceso el 30 de octubre de 2019].

Departamento de Trabajo y J usticia del Gobierno Vasco, 2019. Protocolo de funcionamiento para el servicio de justicia restaurativa [en línea]. VitoriaGasteiz: Gobierno Vasco. Disponible en:

https://www.justizia.eus/servlet/Satellite?blobcol=urldata\&blobheader=applic ation $\% 2$ Fpdf\&blobheadername1 =ContentDisposition\&blobheadervalue1=filename\% 3DPROTOCOLO_FAMI LIA_JUSTICIA RESTAURATIVA 2019 0.pdf\&blobkey=id\&blobtable=MungoBlobs\&blobwhere $\equiv 1290511108410$ \&ssbinary=true [Con acceso el 30 de octubre de 2019].

Estirado de Cabo, C., 2008. Cuestiones relevantes de derecho sustantivo y procesal respecto de la incorporación de la mediación a la jurisdicción penal de adultos en las fases de instrucción y de enjuiciamiento. En: M.C. Pérez-Salazar y J.C. Ríos Martín, eds., La mediación civil y penal: Un año de experiencia. Madrid: CGPJ, pp. 207-215.

Faget, J., 2006. The French phantoms of restorative justice: the institutionalization of "penal mediation". En: I. Aertsen, T. Daems y L. Robert, eds., Institutionalizing Restorative Justice. Cullompton: Willan, pp. 151-166.

García Guillamón, C., 2016. Contextualización del papel del abogado en el marco de la justicia restaurativa: La mediación penal. En: V. Cervelló Donderis, ed., 
Cuestiones prácticas para la aplicación de la mediación penal. Valencia: Tirant lo Blanch, pp. 197-222.

Gavrielides, T., 2007. Restorative Justice Theory and Practice: Addressing the Discrepancy [en línea]. Helsinki: European Institute for Crime Prevention and Control. Disponible en:

https://www.peacepalacelibrary.nl/ebooks/files/HEUNI_8oiteshk6w.pdf [Con acceso el 30 de octubre de 2019].

Gil Gil, A., 2016. Sobre la satisfacción de la víctima como fin de la pena. InDret [en línea], no 4. Disponible en: http://www.indret.com/pdf/1254.pdf [Con acceso el 30 de octubre de 2019].

González Anleo, J., 1994. Las profesiones en la sociedad corporativa. En: J.L. Fernández y A. Hortal, comps., Ética de las profesiones. Madrid: Universidad Pontificia Comillas, pp. 21-34.

Hortal, A., 2004. Ética general de las profesiones. Bilbao: Desclée de Brouwer.

Igartua, I., et al., 2015. Evaluación del coste de la justicia restaurativa integrando indicadores cuantitativos y cualitativos: El caso de la mediación penal aplicada a las infracciones de menor gravedad (Álava, 2013) [en línea]. Departamento de Administración Pública y Justicia del Gobierno Vasco. Vitoria-Gasteiz: Servicio Central de Publicaciones del Gobierno Vasco. Disponible en: http://www. poderjudicial.es/stfls/CGPJ/MEDIACI\%C3\%93N/PUBLICACIONES/ 20170214\% 20COSTE_JUSTICIA_DEFINITIVO_PUBLICADO_G_V_09-022016_2.pdf [Con acceso el 30 de octubre de 2019].

Johnstone, G., y Van Ness, D.W., 2007. The meaning of restorative justice. En: G. J ohnstone y D.W. Van Ness, eds., Handbook of Restorative J ustice. Cullompton: Willan, pp. 5-23.

Lederach, J.P., 2005. The Moral I magination: The Art and Soul of Building Peace. Oxford University Press.

Martín Diz, F., 2010. La mediación: Sistema complementario de Administración de J usticia. Madrid: CGPJ .

Martínez Camps, M.M., 2016. Formación y habilidades de los mediadores. En: V. Cervelló Donderis, ed., Cuestiones prácticas para la aplicación de la mediación penal. Valencia: Tirant lo Blanch, pp. 225-234.

Pascual Rodríguez, E., ed., 2013. Los ojos del otro: Encuentros restaurativos entre víctimas y ex miembros de ETA. Santander: Sal Terrae.

Piñeyroa Sierra, C., et al., 2011. El valor de la palabra que nos humaniza: Seis años de Justicia Restaurativa en Aragón. Zaragoza: Asociación ¿Hablamos?

Pranis, K., 2007. Restorative Values. En: G. Johnstone y D.W. Van Ness, eds., Handbook of Restorative Justice. Cullompton: Willan, pp. 59-74.

Ríos Martín, J., y Olavarría Iglesia, T., 2008. Conclusiones del curso La mediación civil y penal: Dos años de experiencia. En: M.C. Pérez-Salazar y J.C. Ríos Martín, eds., La mediación civil y penal: Un año de experiencia. Madrid: CGPJ, pp. 253-302.

Sáez Rodríguez, C., 2010. Mediación penal: Informe de evaluación y situación. En: J.R. Sáez Valcárcel, dir., Justicia restaurativa y mediación penal. Cuadernos de Formación Judicial, no 51, pp. 5-63.

Sáez Rodríguez, C., 2011. Mediación penal: Conclusiones de las experiencias en España 1998-2011. Cuadernos penales José María Lidón, no 8, pp. 127-190. 
Sáez Valcárcel, R., 2011. Mediación penal: Reconciliación, perdón y delitos muy graves. La emergencia de las víctimas. Cuadernos penales José María Lidón, no 8, pp. 71-125.

Sánchez Álvarez, M.P., 2008. La entrevista individual: Técnicas de intervención. En: M.C. Pérez-Salazar y J.C. Ríos Martín, eds., La mediación civil y penal: Un año de experiencia. Madrid: CGPJ, pp. 159-166.

Soleto Muñoz, H., 2017. La justicia restaurativa, mecanismo adecuado para mejorar la reparación a la víctima en el proceso penal. En: A.M. Carrascosa, ed., Justicia restaurativa y mediación penal. Madrid: CGPJ, Cuadernos de Formación Judicial, no 17, pp. 52-90.

Varona Martínez, G., 2019. Justicia restaurativa y justicia terapéutica. Hacia una praxis reflexiva de transgresiones disciplinares [en línea]. En: E. Pillado González, ed., Hacia un proceso penal más reparador y conciliador: Avances desde la justicia terapéutica. Madrid: Dykinson, pp. 25-56. Disponible en: https://doi.org/10.2307/j.ctvr7f87t.5 [Con acceso el 30 de octubre de 2019].

Zehr, H., 2002. The Little Book of Restorative Justice. Brattleboro, VT: Good Books.

Zehr, H., 2012. Cambiando de lente: Un nuevo enfoque para el crimen y la justicia. Trad.: C.D. Quezada González et al. Harrisonburg, VA: Herald Press.

(Publicado originalmente en inglés en 1990).

\section{Referencias normativas}

Directiva 2012/29/UE, del Parlamento Europeo y del Consejo de 25 de octubre de 2012 por la que se establecen normas mínimas sobre los derechos, el apoyo y la protección de las víctimas de delitos, y por la que se sustituye la Decisión marco 2001/220/JAl del Consejo. Diario Oficial de la Unión Europea [en línea], de 14 de noviembre de 2012, L 315/57. Disponible en:

https://www. boe.es/doue/2012/315/L00057-00073.pdf [Con acceso el 30 de octubre de 2019].

Ley $4 / 2015$, de 27 de abril, de Estatuto de la víctima de delito. Boletín Oficial del Estado [en línea], № 101, de 28 de abril de 2015. Disponible en:

https://www.boe.es/eli/es/1/2015/04/27/4/con [Con acceso el 30 de octubre de 2019].

Ley Orgánica 1/2015, de 30 de marzo, por la que se modifica la Ley Orgánica 10/1995, de 23 de noviembre, del Código Penal. Boletín Oficial del Estado [en línea], no 77, de 31 de marzo de 2015. Disponible en:

https://www.boe.es/eli/es/lo/2015/03/30/1 [Con acceso el 30 de octubre de 2019].

Ley Orgánica 10/1995, de 23 de noviembre, del Código Penal. Boletín Oficial del Estado [en línea], no 281, de 24 de noviembre de 1995. Disponible en: https://www.boe.es/eli/es/lo/1995/11/23/10/con [Con acceso el 30 de octubre de 2019].

Orden de 12 de mayo de 2015, del Consejero de Presidencia y Justicia, por la que se dispone la publicación del convenio marco de colaboración entre el Consejo General del Poder Judicial y la Comunidad Autónoma de Aragón, para la promoción de la mediación intrajudicial. Boletín Oficial de Aragón [en línea], no 109, 10 de junio. Disponible en: http://www.boa.aragon.es/cgibin/EBOA/BRSCGI?CMD =VERDOC\&BASE $=$ BOLE\&PIECE $=$ BOLE\&DOCS $=1-$ $40 \& D O C R=17 \& S E C=F I R M A \& R N G=200 \& S E P A R A D O R=\& \& P U B L=20150610$ [Con acceso el 30 de octubre de 2019].

Proposición no de ley núm. 75/11-viii, sobre justicia reparativa, para su tramitación ante la comisión institucional y de desarrollo estatutario. Boletín Oficial de las Cortes de Aragón [en línea], № 15, de 19 de octubre de 2011. Disponible en: 
http://bases.cortesaragon.es/bases/original.nsf/(BOCA1)/F1A8FAE35ED57E2B C125792F004384AF/\$File/BOCA15.pdf?OpenElement [Con acceso el 30 de octubre de 2019].

Recomendación CM Rec 2018(8) del Comité de Ministros a los Estados miembros en materia de mediación penal. Adoptada por el Comité de Ministros el 3 de octubre de 2018 en la 1326a reunión de los Delegados de los Ministros. (Traducción no oficial encargada y revisada por el Departamento de Trabajo y J usticia del Gobierno Vasco) [en línea]. Vitoria-Gasteiz: Departamento de Trabajo y Justicia, Gobierno Vasco. Disponible en:

https://www.justizia.eus/servlet/Satellite?c=J NET_Documento FA\&cid=12901 81110942 \&pagename $=$ J ustiziaNet\% 2F] NETEnlaceDocu [Con acceso el $30 \mathrm{de}$ octubre de 2019]. 